\title{
Numerical Simulation Analysis of NPR Anchorage Monitoring of Bedding Rock Landslide in Open-Pit Mine
}

\author{
Kai Zhang, ${ }^{1,2}$ Xiaojie Yang, ${ }^{1,2}$ Xuebin Cui, ${ }^{1,2}$ Yong Wang, ${ }^{1,2}$ and Zhigang Tao $\mathbb{D}^{1,2}$ \\ ${ }^{1}$ State Key Laboratory for Geomechanics \& Deep Underground Engineering, China University of Mining \& Technology, \\ Beijing 100083, China \\ ${ }^{2}$ School of Mechanics and Civil Engineering, China University of Mining \& Technology, Beijing 100083, China \\ Correspondence should be addressed to Zhigang Tao; taozhigang@263.net
}

Received 15 July 2019; Revised 16 November 2019; Accepted 25 November 2019; Published 6 January 2020

Academic Editor: Jiang Jin

Copyright (c) 2020 Kai Zhang et al. This is an open access article distributed under the Creative Commons Attribution License, which permits unrestricted use, distribution, and reproduction in any medium, provided the original work is properly cited.

\begin{abstract}
Nanfen open-pit iron mine is the largest single open-pit mine in Asia. Because of the lag of the extension project, the section has slowly spread in the shape of "V," and disasters such as landslides occur frequently. In this study, first, the NPR anchor cable monitoring, which shows supernormal mechanical characteristics and can realize the monitoring and early warning target for the whole landslide process and early warning curve of bedding rock "2016-1101 landslide" in the lower wall of Nanfen open-pit mine, was analyzed, revealing the failure process of the bedding rock landslide and the force evolution characteristics of the NPR anchor cable. Then, based on the Fish language in FLAC3D and 3DEC software, the mechanical model of the NPR anchor cable was constructed, and numerical simulation was performed on the whole process of "16-1101 landslide" induced by accumulation of old landslide body. The results of this study indicate that the stress monitoring curves and failure characteristics of the NPR anchor cables in the whole process of landslide by the two numerical simulation methods are basically consistent with the field measurement results, providing a theoretical and practical basis for the mechanistic analysis and numerical simulation of other similar slopes.
\end{abstract}

\section{Introduction}

Under the blasting, rainfall, and human activity, the rock mass of slope weakens, causing a large number of engineering disasters [1-6]. The disaster because of large deformation during a landslide in an open-pit mine not only causes huge economic losses but also seriously threatens the safety of life and property of the staff in the mine. Reducing the casualties and property losses caused by landslides and forecasting them have been a research hotspot. The key to affecting the reliability and authenticity of forecasting results is to timely and accurately monitor and simulate the data. Based on this, the study and development of landslide monitoring methods have become the most basic measure to improve the effectiveness of the prediction results. At present, the monitoring methods widely used include deformation monitoring, physical field monitoring, water monitoring, and external trigger monitoring [7-10]. Allasia et al. proposed a new method called Advanced Displacement
Monitoring System for Early Warning for near real-time monitoring of surface displacement caused by landslides [11]; Choon et al. monitored and analyzed the slope displacement of Basel coal mine in Indonesia using a GPS system, and a GIS model combining the fuzzy theory and analytical hierarchy process was established to evaluate the slope instability of open-pit mines [12]. In recent years, satellite remote sensing technology monitoring methods (SAR, INSAR, and D-INSAR) have been widely used in landslide monitoring leading to significant results [13-16]. Based on previous investigation and our experience with Saito's method, an improved Saito curve was drawn with four stages corresponding to the displacement process of the position on the back of the landslide [17]. However, these landslide monitoring methods are basically based on observing the surface displacement, cracks, and settlements. These factors are necessary conditions for the occurrence of landslides rather than sufficient conditions. Therefore, carrying out the advance warning of landslide disasters is 
impossible. He et al. proposed that "sliding force is greater than the shear strength, and it is the necessary and sufficient condition for landslide generation." Based on this, they constructed the mechanical model of "sliding force monitoring" and developed an NPR anchor cable with constant resistance characteristics, which can adapt to landslide monitoring in deep deformation conditions [18-21]. On this basis, a wireless sensor network was built based on the GPRS dual-channel platform using Zigbee technology, and a multisource system cloud service platform was established for landslide monitoring to adapt to the complex environment sloping disaster monitoring and early warning system [22-26]. Although they successfully monitored and warned of many dangerous landslides, they neither established the NPR anchor cable numerical calculation model and nor carried out the numerical simulation of the whole process of landslide monitoring and early warning.

Similarly, the numerical simulation analysis of landslide geological disasters is also a key method for investigation in the field of slope engineering. At present, a series of numerical methods such as finite difference method and finite volume method for different types of sliding bodies have been developed. Model establishment and control theory include discrete element method (DEM), discontinuous deformation, DAN, smooth particle hydrodynamics, particle flow code (PFC), and tsunami ball. Some numerical simulation software such as FLAC, UDEC, PFC, 3DEC, and Geoslope have emerged. Many researchers carried out a series of simulations on the slope instability and damage by these methods and software achieving significant results. Maihemuti et al. used the three-dimensional rapid Lagrangian analysis program (FLAC3D, 4.0) of geotechnical engineering to numerically simulate the deformation and failure process of the bank slope rock and obtained the deformation mechanism of the E20 bank slope [27]. Li et al. combined $\mathrm{C}++$ programming technology and finite difference method and realized the three-dimensional numerical simulation of slope through the intelligent inversion analysis of the structural parameters of the soil slope [28]. The traditional continuous numerical calculation method has been widely used by the predecessors, and the practicability and effectiveness of the finite element method and boundary element method have been fully confirmed [29-32]. At the same time, Munjiza et al. combined the finite element method suitable for the analysis of continuous problems with the discrete element method suitable for transient, contact detection, contact interaction, and other discrete problems [33]. Some scholars explored the integrated continuity and discontinuity methods, known as the finite element-discrete element method for the numerical simulation of material cracking and fracture after slope instability [34-37]. However, the NPR anchor cable monitoring, numerical modeling, and simulation analysis in the whole process of landslides are rarely investigated. Based on the monitoring data and the engineering geological conditions of "2016-1101 landslide," in this study, we established the NPR anchor cable numerical calculation model and carried out numerical simulation on the monitoring of "2016-1101 landslide" through the Fish language in FLAC3D and 3DEC software. The whole process of monitoring and early warning of Newtonian force of typical landslide in Nanfen open-pit mine was established, laying a good theoretical foundation for the layout of the monitoring points of the Newtonian force and slope stability analysis in Nanfen openpit mine in the future.

\section{Structural Composition and Static Tensile Mechanical Properties of the NPR Anchor Cable}

2.1. Structural Composition of the NPR Anchor Cable. The NPR anchor cable is different from the traditional PR anchor cable and has improved constant resistance and large deformation mechanical characteristics. Figure 1 shows the structural composition of the NPR anchor cable, mainly including mechanical sensors, anchor cables (steel strands), constant resistance bodies, constant resistance bushings, top covers, backing plates, filling new materials, and other equipment.

Normally, the force applied on the anchor cable is offset by the static friction between the constant resistance body and the constant resistance casing. When the load applied to the anchor cable is larger than the constant resistance design load value, the body begins to move along the inner wall of the casing and absorbs the load energy through the structural deformation, leading to constant resistance and large deformation.

2.2. The Mechanical Model for NPR Anchor Cable. The constant resistance body is the core part of the constant resistance and large deformation anchor cable, and its structure is shown in Figure 2 [18].

Among them, $\alpha$ is the angle of constant resistance body, $h$ is the effective length of constant resistance body, $a$ is the inner radius of constant resistance casing, $b$ is the outer radius of constant resistance casing, $u$ is the radial deformation, $V$ is the elongation of anchor cable bundle, $P_{0}$ is the external load, $M$ is the mass of constant resistance body, $\delta(z)$ is the inner wall deformation of constant resistance casing of $A-B$ section at $z$ from the top of constant resistance body, $p^{\prime}$ is the acting stress of constant resistance body to constant resistance casing, and $p^{\prime}(z)$ is the action stress of $A-B$ profile constant resistance casing to constant resistance body. The mechanical model of the rheostat is as follows [18]:

$$
\begin{aligned}
& P_{0}=2 \pi f I_{s} I_{c}, \\
& I_{s}=\frac{E\left(b^{2}-a^{2}\right) \tan \alpha}{a\left[a^{2}+b^{2}-\mu\left(b^{2}-a^{2}\right)\right]}, \\
& I_{c}=\frac{a h^{2}}{2} \cos \alpha+\frac{h^{3}}{3} \sin \alpha,
\end{aligned}
$$

where $P_{0}$ is the constant resistance $(\mathrm{kN}), f$ is the static friction coefficient, $I_{s}$ is the elastic constant of the constant resistance sleeve, $I_{C}$ is the geometric constant of the constant 


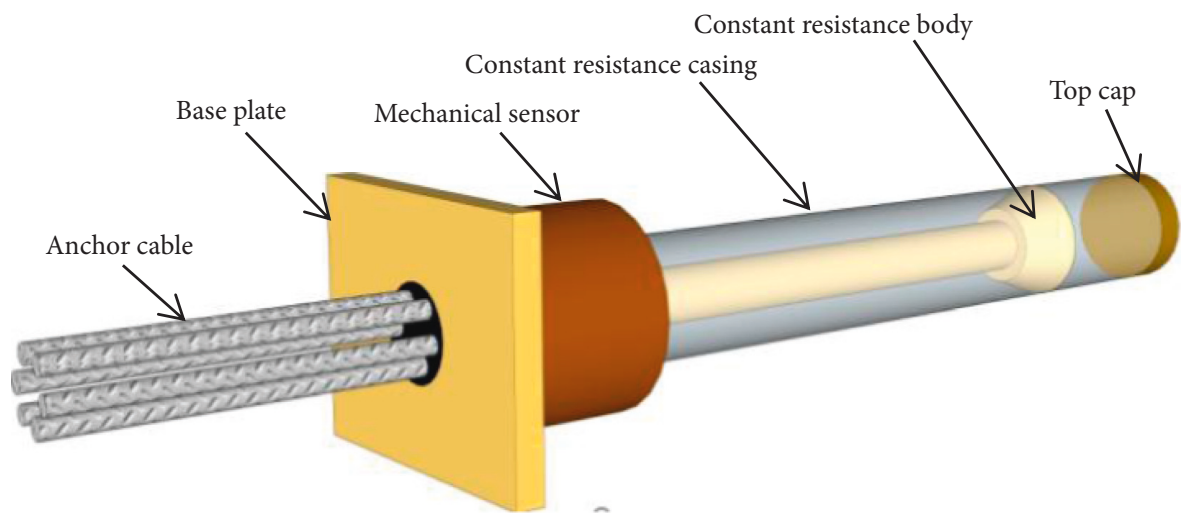

FIGURE 1: Structure diagram of constant resistance large deformation anchor cable.

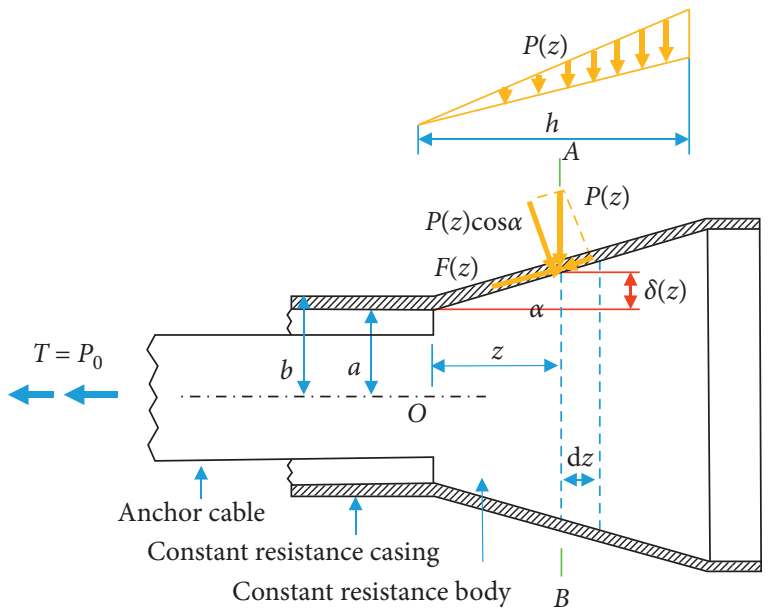

Figure 2: Analysis of the axial stress of the constant resistance device.

resistance body, $E$ is the elastic modulus of the material, and $\mu$ is Poisson's ratio of the material.

The constant resistance value of the NPR anchor cable is related to the material size of the constant resistance body and the external load.

\subsection{Extraordinary Statics and Its Test}

2.3.1. Testing System. In order to verify and investigate the supermechanical properties such as tensile properties, negative Poisson's ratio (NPR) characteristics, and constant resistance specialty of the anchor cables in this study, we used "the static tensile test system of HWL-2000 NPR anchor cables," developed by the State Key Laboratory of Deep Geotechnical Mechanics and Underground Engineering, China University of Mining and Technology (Beijing). The anchor cables are numbered as "MS-01-01," "MS-01-02," and "MS-01-03," and their physical parameters are listed in Table 1.

The test system mainly includes a data acquisition and processing system, a liquid crystal display system, a hydraulic power system, and an anchorage and tension system. The maximum tensile force is $2,000 \mathrm{kN}$; the resolution of the tensile force is $3.3 \times 10^{-6}$; and the strain rate and tension are in the ranges $0-200 \mathrm{~mm} / \mathrm{min}$ and $30-5000 \mathrm{~mm}$, respectively. Figure 3 shows the schematic diagram of the static stretching system.

\subsubsection{Result Analysis}

(1) Tensile properties and constant resistance characteristics of the constant resistance and large deformation anchor cables

Figure 4 shows the static tensile test curve of the test piece anchor cable, indicating the following:

(a) From the beginning of the tension to the failure of the anchor cable, it has an average elongation of $1960 \mathrm{~mm}$, showing an extraordinarily large deformation capacity.

(b) During the static tension, the axial force of the anchor cable rises to the maximum constant resistance $(850 \mathrm{kN})$ in a short time and then becomes constant at $850 \mathrm{kN}$, exhibiting a remarkable constant resistance characteristic.

(2) Negative Poisson's ratio effect of the constant resistance large deformation anchor cable structure

The cable structure with a constant resistance and large deformation under axial elongation also undergoes radial structural expansion. Figure 5 shows the NPR anchor cable resistor used in the experiment.

The outer diameters of the cross sections 1-1 and 2-2 in two vertical directions were measured using a Vernier caliper. The interval is $100 \mathrm{~mm}$, and the length of the casing is read. Figures 6(a) and 6(b) show the diameters of the three groups of the constant resistance casing in 1-1 and 2-2 directions, respectively.

(1) The initial average diameters before and after the test in the 1-1 direction are $121.42 \mathrm{~mm}$ and $\sim 125.42 \mathrm{~mm}$, respectively. The expansion in the 1-1 direction before and after the test is $\sim 4 \mathrm{~mm}$.

(2) The initial average diameters before and after the test in the 2-2 direction are 121.50 and $\sim 125.66 \mathrm{~mm}$, 
TABLE 1: Anchor cable parameters.

\begin{tabular}{lccc}
\hline $\begin{array}{l}\text { Anchor cable } \\
\text { number }\end{array}$ & Anchor cable length $L_{1}(\mathrm{~mm})$ & $\begin{array}{c}\text { Constant resistance sleeve length } L_{2} \\
(\mathrm{~mm})\end{array}$ & $\begin{array}{c}\text { Constant resistance body length } L_{3} \\
(\mathrm{~mm})\end{array}$ \\
\hline MS-01-01 & 2854 & 2005 & 150 \\
MS-01-02 & 2856 & 2007 & 150 \\
MS-01-03 & 2860 & 2010 & 150 \\
\hline
\end{tabular}

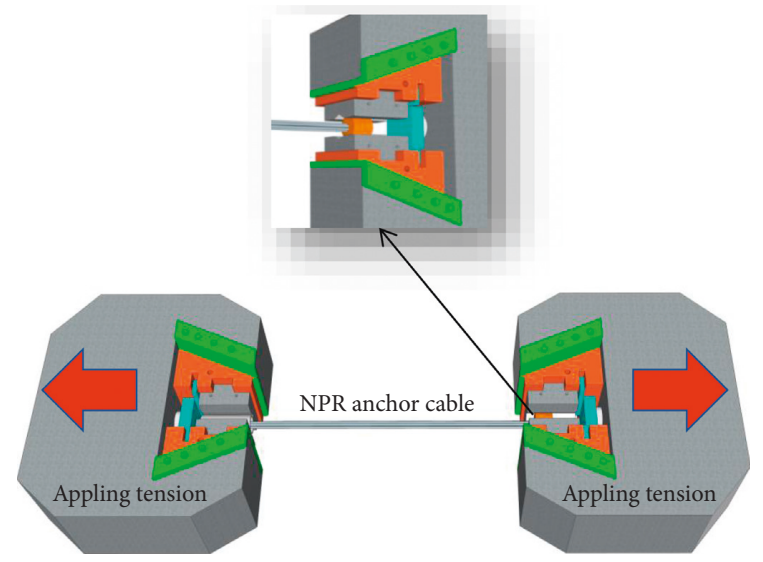

FIGURE 3: Schematic diagram of the static stretching system.

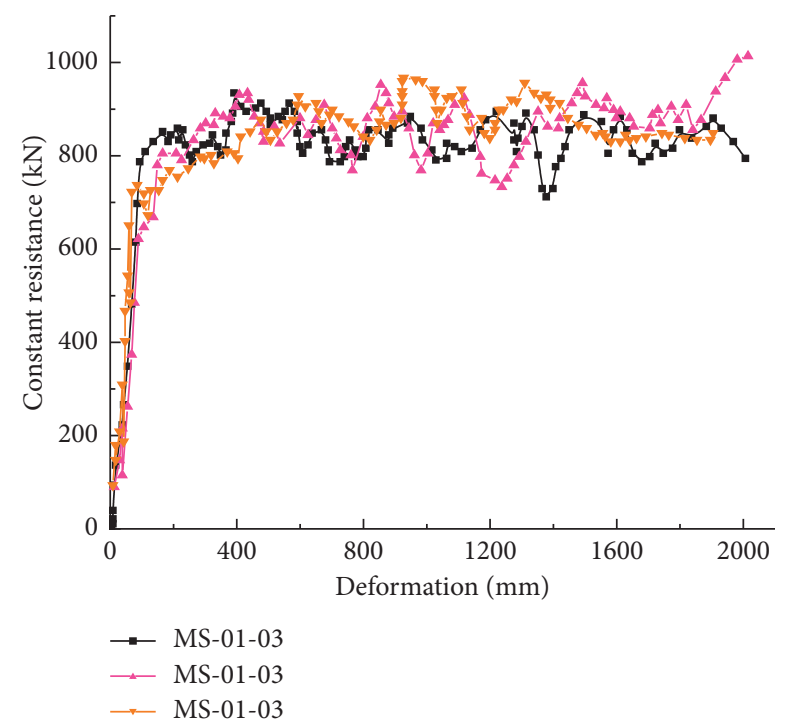

Figure 4: Static tensile test curve of the anchor cable.

respectively. The expansion in the 2-2 direction before and after the test is $\sim 4.16 \mathrm{~mm}$.

In summary, the large deformation anchor cable with a constant resistance has supernormal tensile properties, NPR characteristics, and constant resistance characteristics.

(3) Geological conditions, landslide monitoring system, and distribution characteristics of monitoring point.

3.1. Topography, Geomorphology, and Stratigraphic Lithology. Nanfen open-pit iron mine (Figure 7) of the Benxi Steel Group is located $25 \mathrm{~km}$ south of Benxi City, Liaoning

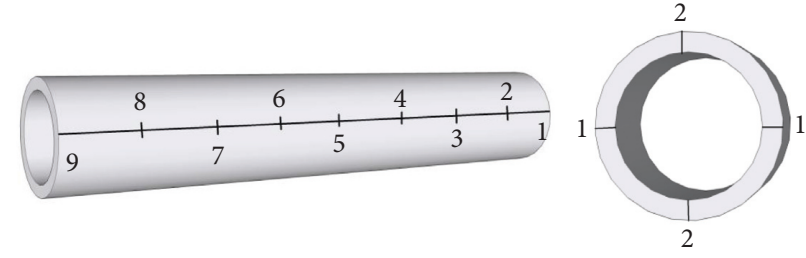

FIGURE 5: NPR anchor cable resistor.

Province. Its terrain undulates greatly. The relative elevation difference is generally $300-400 \mathrm{~m}$, and the maximum elevation is $500 \mathrm{~m}$. The overall topography is high in the east and low in the west, and the mountain trend is close to the east and west. It is a middle-high mountain area with a denudation structure. The orebody is a monoclinic structure. The east and west sides of the stope are the lower and upper walls of the monoclinic structure, respectively.

The strata in the stope are relatively complex. First, the Anshan group (mainly composed of mica quartz schist, epidote amphibolite schist, magnetite quartz, quartz chlorite schist, mica quartz schist, and gneissic migmatite) was widely developed, followed by the Liaohe group of the Proterozoic (mainly composed of quartzite, phyllite, and marble), sinian strata (mainly composed of quartzite and shale), and the quaternary strata of the Cenozoic (lithologically including sand, gravel, clay soil, and gravel).

\subsection{Geological Structure and Hydrometeorological} Characteristics. The geological structure in the mining is the fold structure and fault structure dominated by the inverted anticline (the inverted dome structure of the Heibeishan mountain, the inverted anticline of the openpit mine, and the F1 fault structure). The core drilling data show obvious inverted anticline morphology and fault structure (Figure 8).

The mining area belongs to the north temperate monsoon climate. The annual average rainfall and the maximum daily rainfall are close to 900 and $300 \mathrm{~mm}$, respectively. Rainfall mainly concentrates in the summer. Besides, the annual temperature difference is relatively large; the extreme minimum temperature in the winter is close to $-33^{\circ} \mathrm{C}$, while the extreme maximum temperature in the summer is close to $38^{\circ} \mathrm{C}$; and the annual average temperature is $8.2^{\circ} \mathrm{C}$. Groundwater also plays an important role in the region. The ice and snow melt in the rainy and winter-spring alternating seasons. The water seriously affects the stability of the landslide body, thus increasing the difficulty in mining operations. 


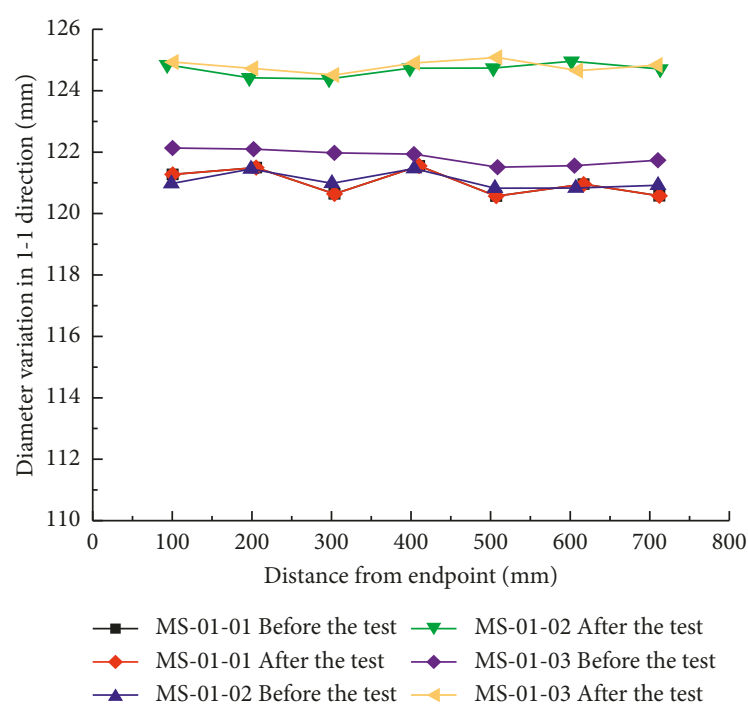

(a)

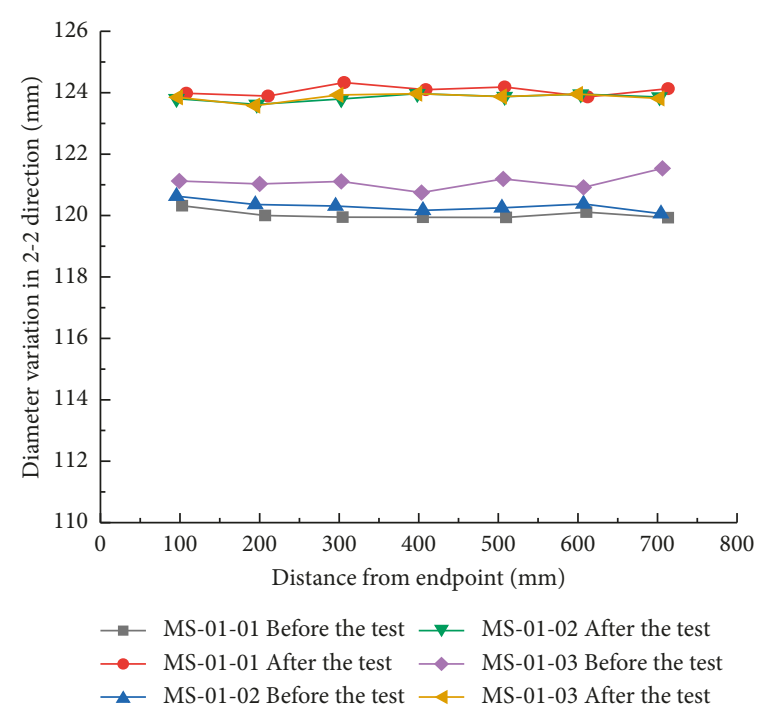

(b)

FIgURe 6: Diameter variation of constant resistance casing before and after the test: (a) diameter variation of 1-1 section; (b) diameter variation of 2-2 section.

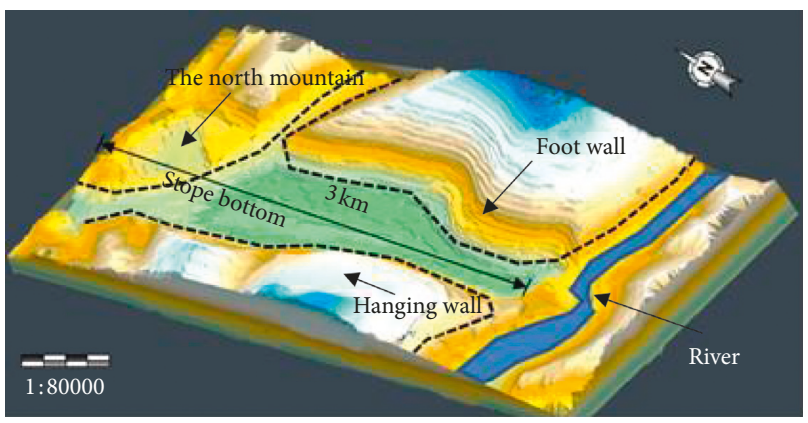

Figure 7: Mine mining site shape and landform.

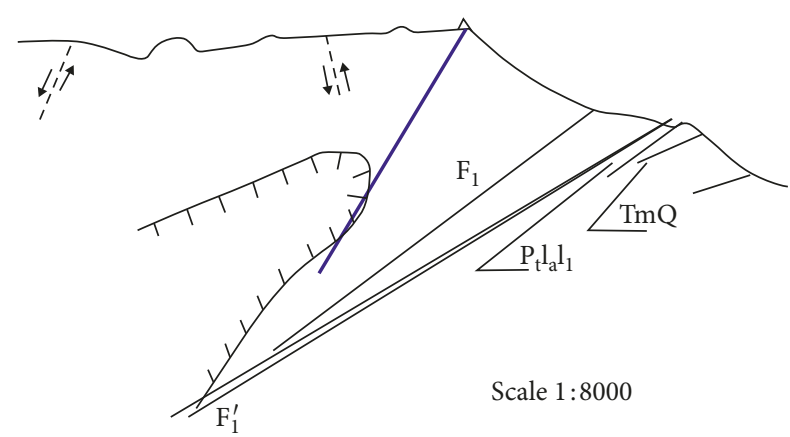

Figure 8: Reverse anticline shape and fault structure in the mining area.

\subsection{Distribution Characteristics of Monitoring Point}

3.3.1. Monitoring System. The landslide observation system is divided into indoor and outdoor monitoring systems.

The indoor landslide monitoring system (Figure 9) mainly consists of a GPRS data receiver, a BeiDou satellite signal receiver, an automatic data analysis and processing

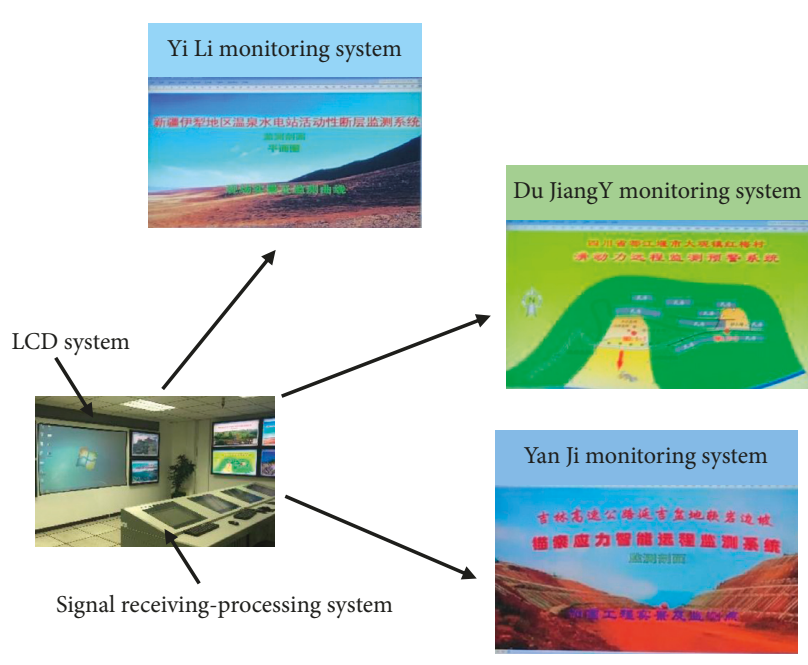

Figure 9: Indoor monitoring system.

system, a 3D automatic search system, and a liquid crystal display system.

The outdoor landslide monitoring system (Figure 10) mainly consists of a signal transmission system, a power supply system, a mechanical transmission device, and a mechanical signal acquisition and conversion device. Among them, the power supply system contains $100 \mathrm{a}$ colloidal battery overcharge, a $85 \mathrm{~W}$ monocrystalline silicon solar panel, and a dedicated controller, guaranteeing $24 \mathrm{~h}$ of working status. The mechanical transmission devices include mechanical sensors. The signal transmission system includes a BeiDou machine and an antenna. There are also anchored piers, poles, and other equipment.

Data transmission and aggregation in the monitoring area are mainly based on the data transmission topology (Figure 11). 


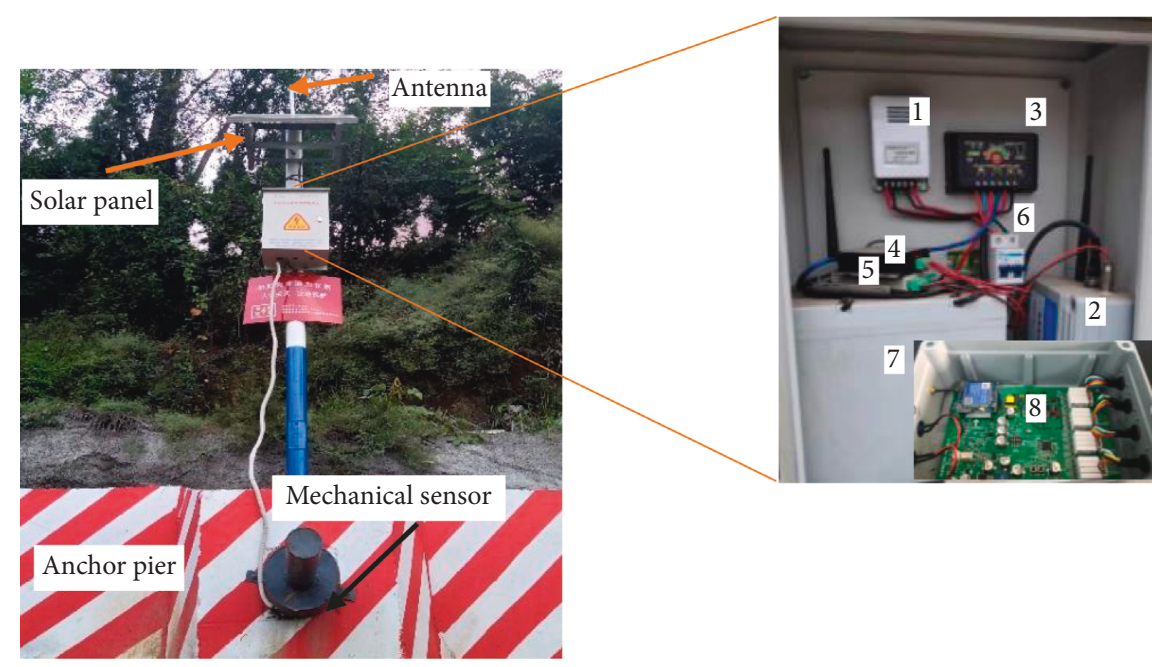

FIGURE 10: Outdoor system equipment: 1, power supply (12 V); 2, power supply (9 V); 3, solar controller; 4, communication node; 5, GPRSDTU; 6, switch; 7, solar battery; 8 , data acquisition device.

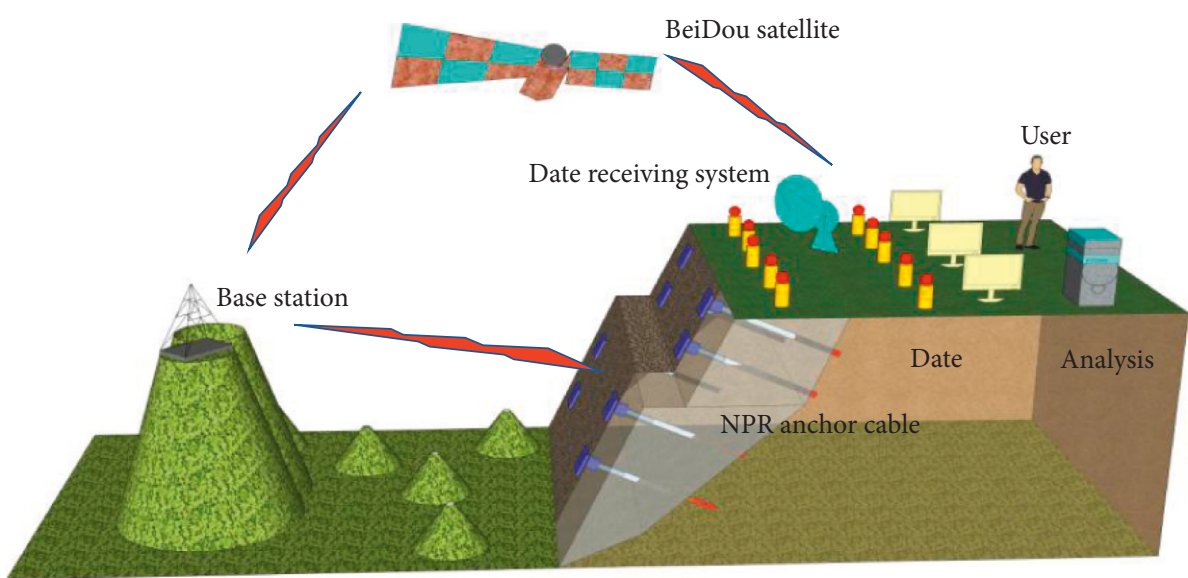

FIGURE 11: Data transmission topology.

3.3.2. Mechanism of Large Deformation Control. NPR anchor cable plays an important role in controlling the large deformation of the slope:

(1) Before the slope slides (Figure 12(a)): assembly of a new anchor cable equipment and application of prestress

Before excavation, the slope is in equilibrium. According to the survey and construction design, holes are drilled in the design depth, the anchor cable is extended into the tunnel, and the anchorage section is grouted and reinforced; besides, the free end is molded, and the installation of equipment is completed, followed by applying the prestressing force.

(2) Slope sliding (Figure 12(b)): energy absorption process of the "NPR structure"

When the slope is about to slip or begin to slip, the original mechanical equilibrium state between the slope and NPR anchor cable will be destroyed, causing slip. As the slip exceeds a certain limit, the constant resistance body will absorb energy with increasing deformation in the casing, effectively increasing or avoiding the breaking of the anchor cable, thus avoiding the sudden collapse of the slope and the failure of the monitoring equipment.

(3) After the slope slides (Figure 12(c)): controlling the sliding body

In the case of large deformation, the elastic energy is released, the deformation energy inside the slope is less than the design constant resistance $\mathrm{P}$ of the resistor, the axial force $\mathrm{F}$ of the anchor cable is less than the friction force, and the soil body reaches a new equilibrium and stable state.

Therefore, the anchor cable can not only realize the monitoring and early warning of the slope landslide but also reinforces the slope.

3.3.3. Distribution Characteristics of the Monitoring Point. With the continuous exploitation of deep mineral resources, landslides, rolling stones, and other geological disasters 

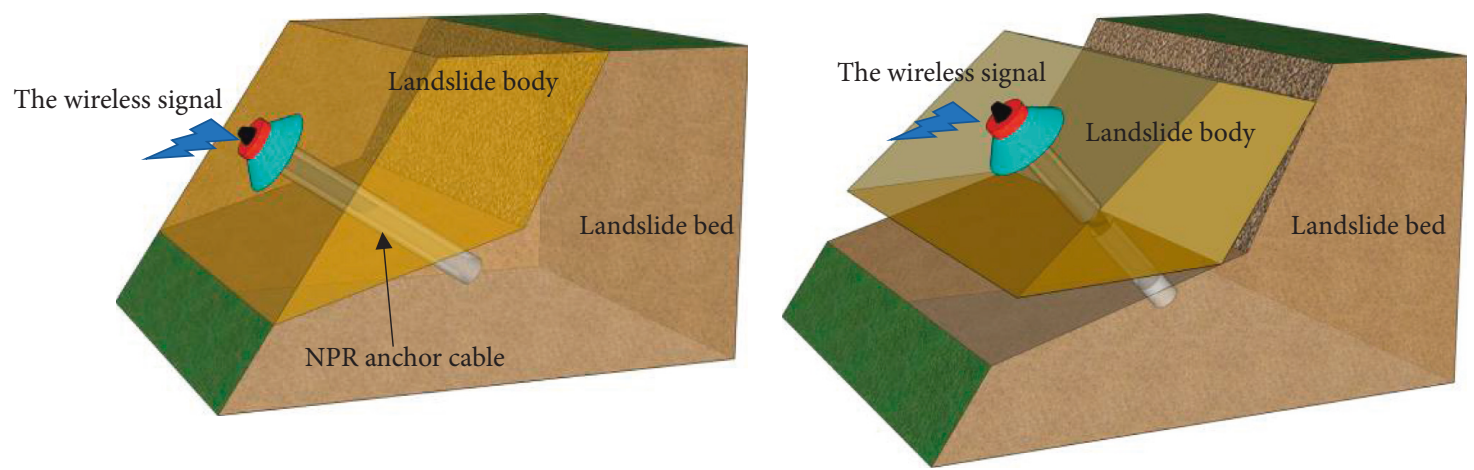

(a)

(b)

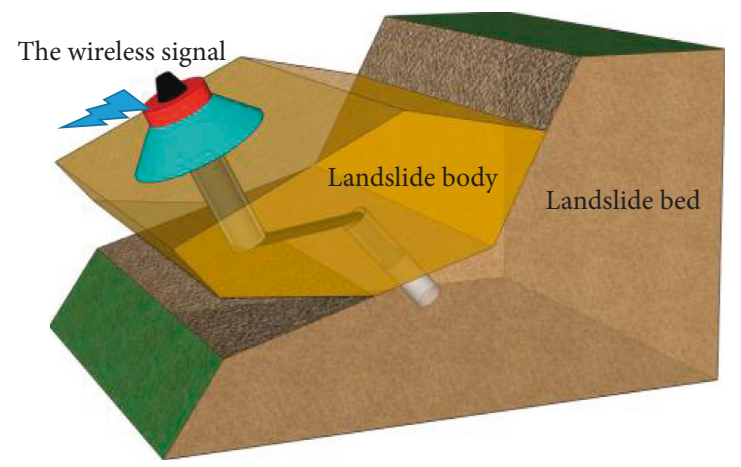

(c)

Figure 12: Process of interaction between NPR anchor and slope: (a) before the slope slides; (b) slope sliding; (c) after the slope slides.

occur frequently. In June 2015, nine new NPR anchor monitoring points were introduced in the $478-502 \mathrm{~m}$ platform range of the stope working face. The buried depth is in the range $55-84 \mathrm{~m}$, the angle of incidence is $45^{\circ}$, and the azimuth angle is $84^{\circ}$. As shown in Figure 13(a), the red marking dots are the new monitoring points, and the $\mathrm{A}-\mathrm{A}^{\prime}$ section of the monitoring area is shown in Figure 13(b).

\section{Numerical Simulation and Analysis of "16- 1101 Landslide" NPR Monitoring}

4.1. Characteristic Analysis of "16-1101 Landslide". At 8:30 on September $14^{\text {th }}, 2016$, the No. $478-3$ curve rose to point $D$, and the system issued a "long-term warning"; at 10:20 on October $1^{\text {st }}, 2016$, because of a working shovel under $430 \mathrm{~m}$ steps, the sliding force curve of No. 478-3 suddenly rose to point $F$, and the system issued a "medium-term warning." The mine leaders asked all large machinery and extension workers to evacuate; at 23:52 on October $31^{\text {st }}, 2016$, the curve suddenly appeared. On November $1^{\text {st }}, 2016$, at 3:40, the monitoring system reported the occurrence of the landslide, producing a loud noise. The broken rock and soil mass rolled down along the slope and piled up on the $430 \mathrm{~m}$ step. The failure characteristics of the slope top behind the landslide are shown in Figure 14.

4.2. Numerical Simulation Analysis of the "16-1101" Landslide. In this section, the field monitoring data of "16-1101 landslide" in Nanfen open-pit iron mine was calculated by
FLAC3D and 3DEC numerical simulation software to realize the recurrence of the landslide process. The numerical analysis model of the NPR anchor cable was constructed by Fish language in numerical simulation software. The model was analyzed, and the calculation was performed for the 161101 landslide to investigate the similarities and differences between the simulation and the actual monitoring results.

4.2.1. Principle of Large Deformation Design of NPR Anchor Cable in Numerical Simulation Software. The NPR anchor reinforcement unit is generally defined by geometric parameters, material parameters, and anchorage agent characteristics. The axial stiffness of the bolt $K$ is expressed by

$$
K=\frac{A E}{L}
$$

where $A$ is the cross-sectional area of the reinforcement, $E$ is the elastic modulus of the bolt, and $L$ is the length of the bolt.

Conventional anchor cables do not have large deformation characteristics. For the NPR anchor cables, with constant resistance and large deformation characteristics, it is necessary to set the end of the anchor section with conventional anchorage strength and the end of the free section as the rigid contact with the rock mass through Fish language in the modeling process. The principle of large deformation is as follows: applying axial force at the end of the NPR anchor cable, when the axial force reaches the design constant resistance $P$, the anchor cable will produce axial deformation, until the maximum deformation is 


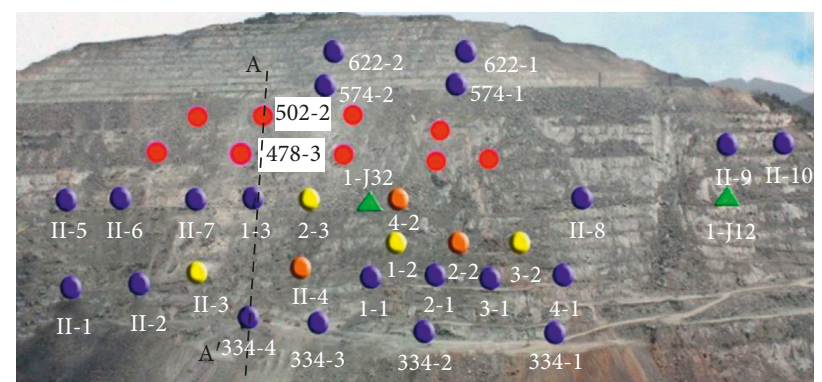

(a)

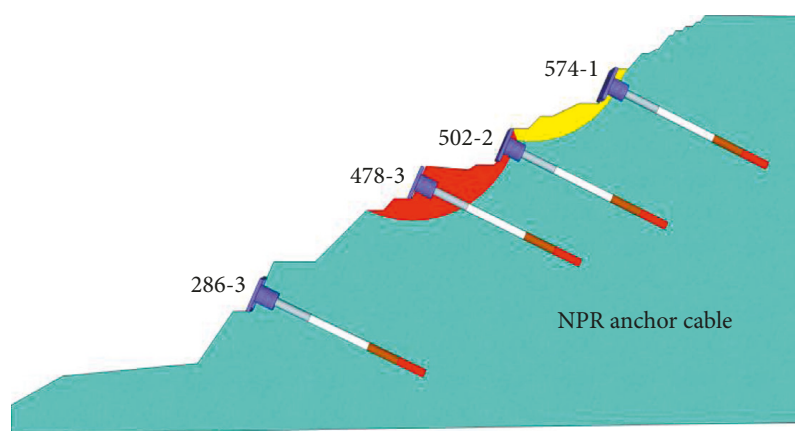

(b)

FIGURE 13: Monitoring point distribution: (a) added monitoring point distribution characteristics; (b) section A- $\mathrm{A}^{\prime}$ of the monitoring area.

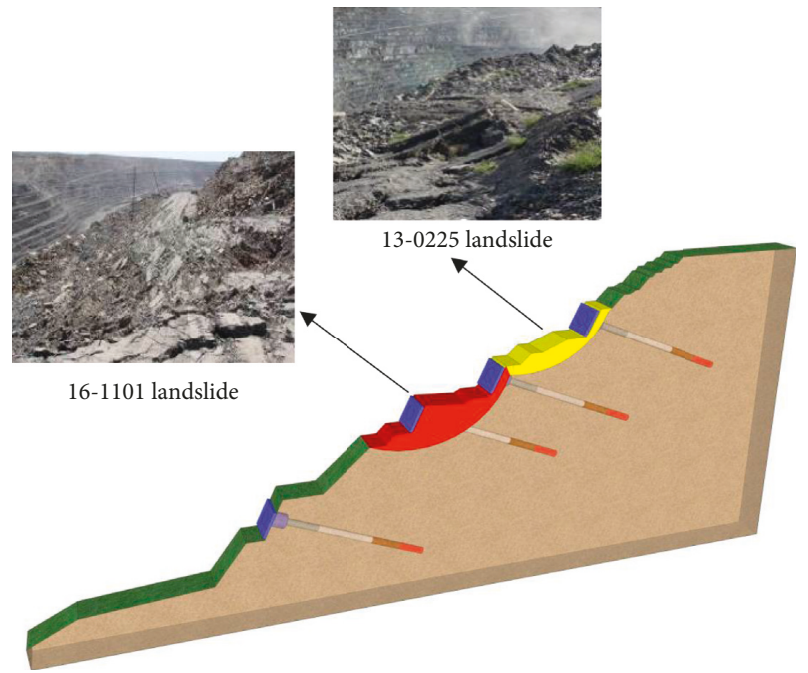

FIGURE 14: Characteristics of the "16-1101 landslide."

reached, the failure of anchorage agent will be judged, and the anchor cable unit will be released to achieve the effect of large deformation.

4.2.2. Numerical Model Establishment of the 16-1101 Landslide. Calibration of model boundary and elevation: the maximum width of the old landslide body and "16-1101 landslide body" is $50 \mathrm{~m}$, and the elevation limits are in the ranges $502-550 \mathrm{~m}$ and $430-502 \mathrm{~m}$. Because the width of the model boundary is 2.5 times larger than the width of the target body, the height range of the model is $277-634 \mathrm{~m}$, and the strike direction length is $200 \mathrm{~m}$. In order to simulate the spatial relationship between the upper and lower sliding bodies and the interface characteristics of the sliding body during the start-up process, setting the interface elements between the sliding body and the rock foundation is necessary. The back, bottom, and both sides of the landslide body have a fixed boundary, and the upper and front parts have a free boundary.

\subsubsection{Landslide Numerical Simulation Based on FLAC3D.} The NPR anchor cable model was constructed by FLAC3D software, as shown in Figure 15. The static tensile mechanical properties are shown in Figure 16.

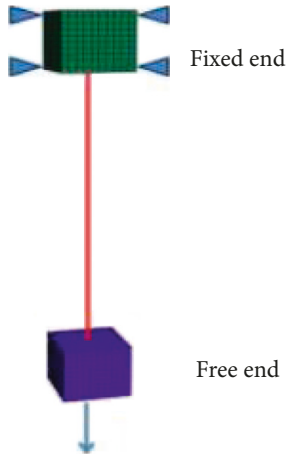

FIgURE 15: The NPR anchor cable model.

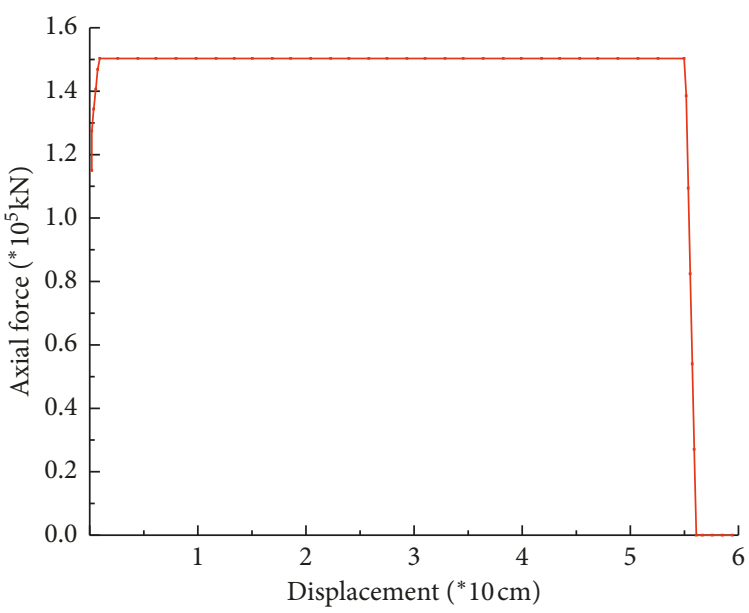

FIGURE 16: The static tensile mechanical properties.

(1) Insertion of the NPR Anchor Cable Model. The parameters of the NPR anchor cable model were determined by the coordinates of the monitoring points of the deep sliding force and buried depth of the NPR anchor cable: inclination angle, $30^{\circ}$; length, $75 \mathrm{~m}$; preload force, $40 \mathrm{kN}$; and constant resistance value, $85 \mathrm{kN}$. The excavation length of the 430 platform shovel is set to $70 \mathrm{~m}$. The rock mechanical parameters are as follows (Table 2).

Figure 17 shows the double-sliding body model. 
TABLE 2: Parameters of rock mechanics.

\begin{tabular}{lcccccc}
\hline Rock mass name & $\begin{array}{c}\text { Bulk weight } \\
\left(\mathrm{kg} / \mathrm{m}^{3}\right)\end{array}$ & Bulk modulus $(\mathrm{GPa})$ & Shear modulus $(\mathrm{GPa})$ & Cohesion $(\mathrm{kPa})$ & Friction angle $\left(^{\circ}\right)$ & Tensile strength $(\mathrm{MPa})$ \\
\hline Basement & 2873 & 20 & 10.9 & 420 & 36 & 1.5 \\
Sliding mass & 2580 & 5.2 & 2.10 & 70 & 27 & 0.2 \\
\hline
\end{tabular}

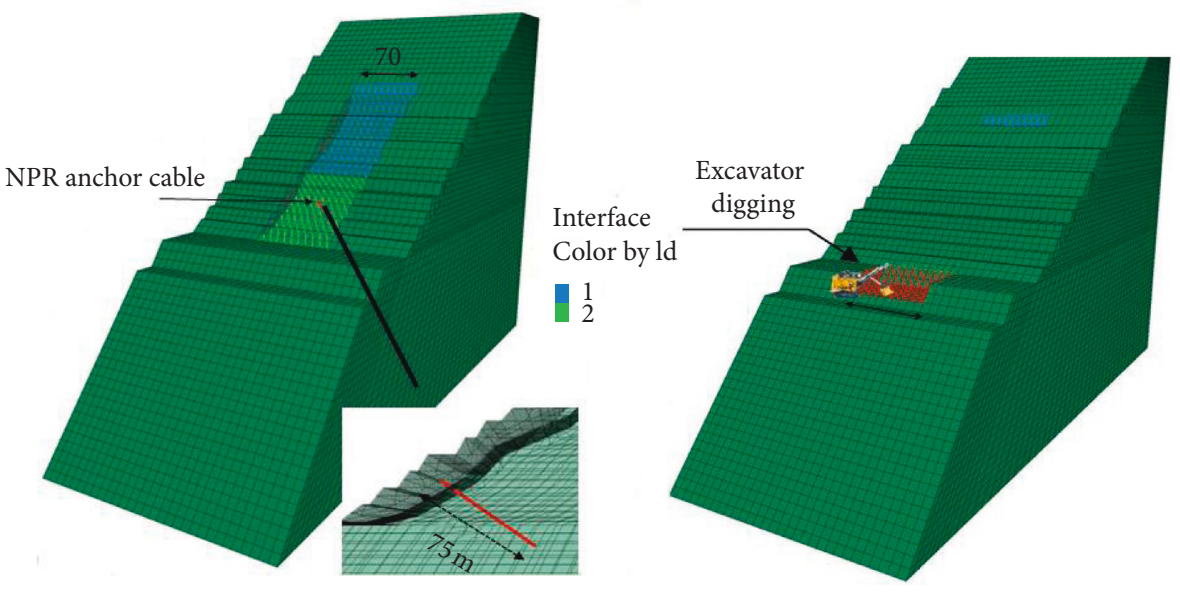

FIgURE 17: Construction of double-sliding body model.

(2) Analysis of Simulation Results

(i) Numerical simulation analysis of the old landslide (Figure 18)

Principles of simulation:

(a) When the maximum unbalance force $F$ is $<1 e-5$, the software determines the landslide as stable.

(b) When the calculation exceeds 10,000 steps and the model is still unstable, the calculation is stopped, and the model is considered to be in a plastic flow state.

(c) Observe the strain increment contour of the sliding surface. When the sliding surface passes through, the software determines the sliding surface instability and stops calculation.

According to these three principles, the maximum displacement of the old landslide after stabilization is $\sim 1.3 \mathrm{~m}$. The landslide body is basically located at the set position of the contact surface of the model. When the slope slides, the strength of the contact surface is set as the actual strength of the sliding surface and then slides until reaching the stable state.

(ii) Numerical simulation analysis of "16-1101 landslide" (Figure 19)

The numerical simulation of "16-1101 landslide" was carried out by setting both the velocity and deformation of the old landslide in the calculation as zero.

After the appearance of "16-1101 landslide," the old landslide body "resurrected" and then slipped, and the $502 \mathrm{~m}$ step appeared staggered. The direct cause of the ultimate

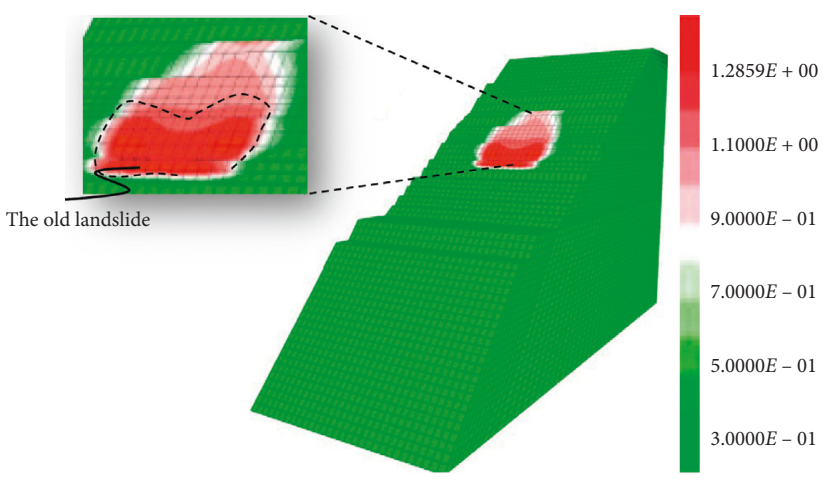

FIGURE 18: Displacement contour of the old landslide after stabilization.

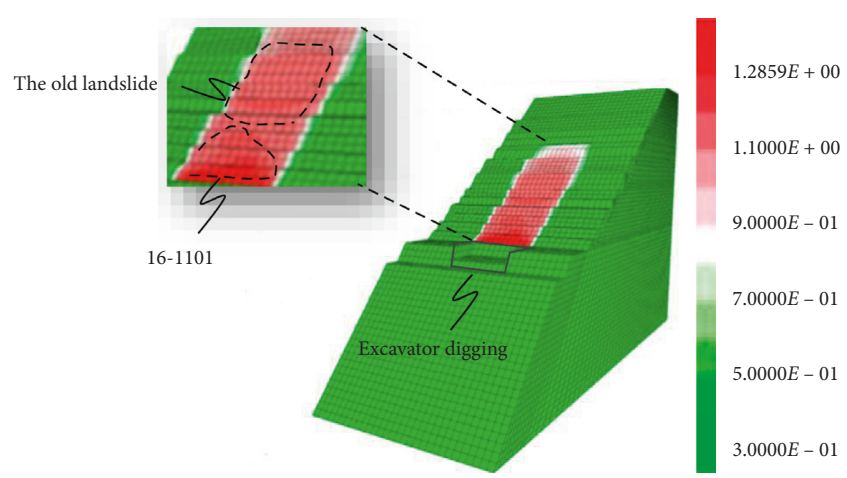

Figure 19: “16-1101 landslide” instability displacement contour.

instability of the whole slope is the transfixion of the sliding surface, and the antisliding force is less than the sliding force. Therefore, in practical calculation, the strength of the contact 
TABle 3: Strength degradation stages criteria.

\begin{tabular}{lcccc}
\hline Stage classification & Normal stiffness $(\mathrm{GPa})$ & Tangential stiffness $(\mathrm{GPa})$ & Cohesive strength $(\mathrm{kPa})$ & Friction angle $\left(^{\circ}\right)$ \\
\hline First stage & 10 & 10 & 148 & 21 \\
Second stage & 10 & 10 & 36 & 25 \\
Third stage & 10 & 10 & 18 & 19 \\
Fourth stage & 10 & 10 & 18 \\
\hline
\end{tabular}

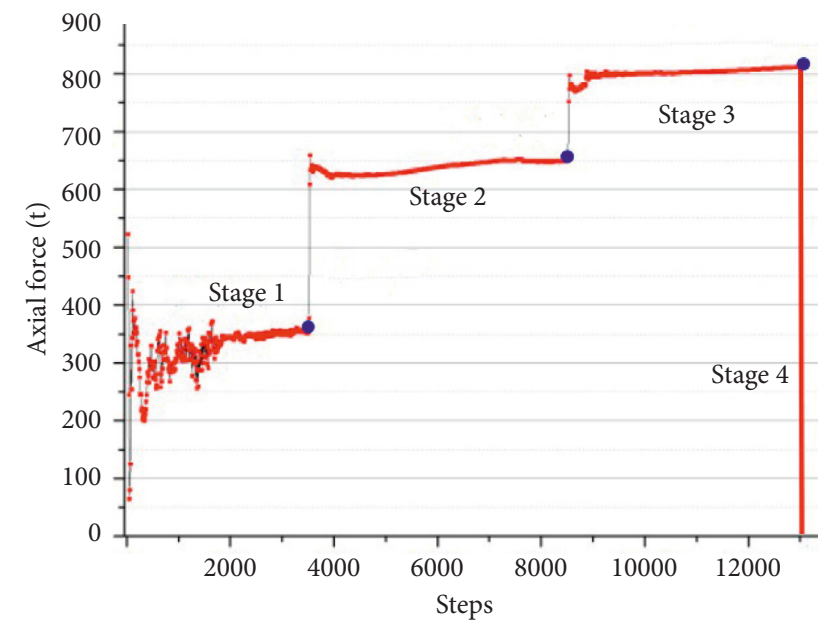

FIgURE 20: Stairs of axis force change of NPR anchor cables.

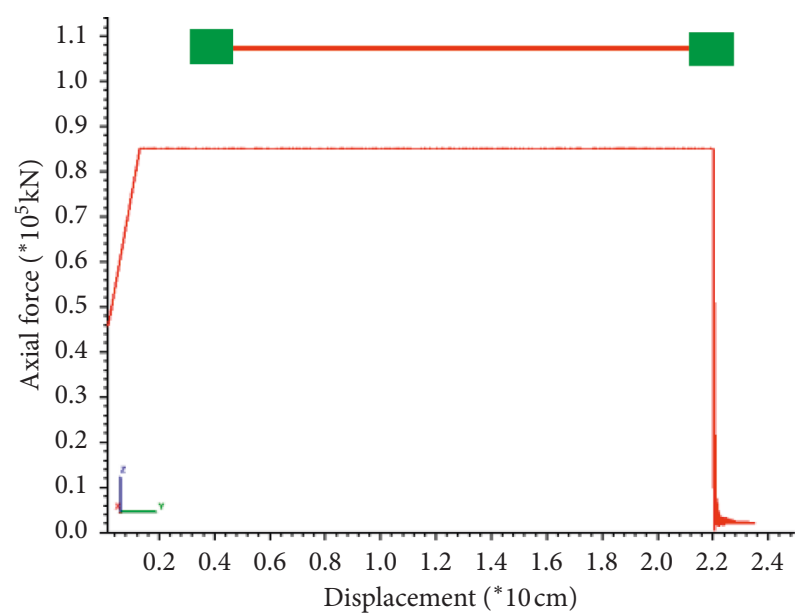

FIGURE 21: NPR anchor cable model and its static tensile properties.

surface (sliding surface) should also be decreased in stages to investigate the rock mass instability. The strength of the contact surface should be divided into stages from the stable state to the final sliding state, as listed in Table 3.

The axial force variation in the NPR anchor cables located at $478 \mathrm{~m}$ steps in the landslide body is also divided into four stages, as shown in Figure 20.

The four stages shown in Figure 20 are as follows:

Stage 1 (shovel excavation at the foot of the slope): the axial force of the NPR anchor cable increases gradually because of the disturbance of shovel excavation on the $430 \mathrm{~m}$ steps.

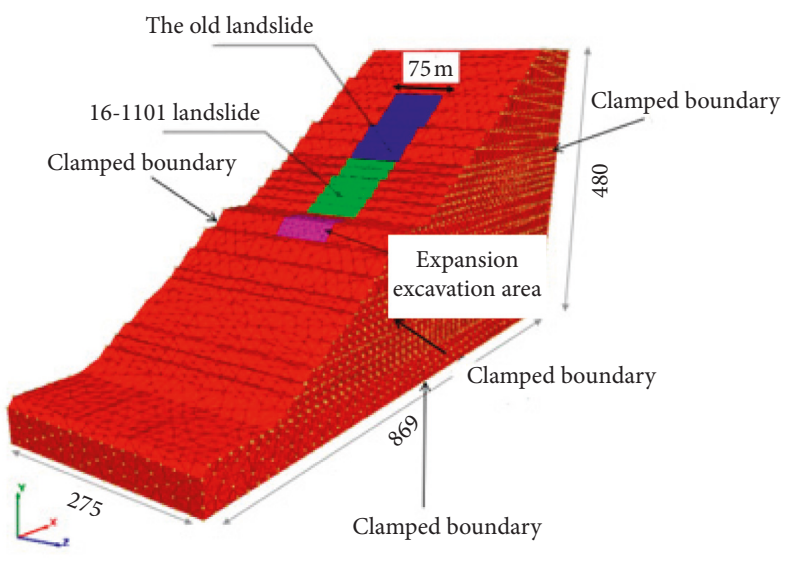

Figure 22: Model building and meshing.

Stage 2 (old sliding body revival): with the excavation of the electric shovel, the sliding force of the slope increases, the old sliding body revives, the strength of the weak interlayer of the sliding surface decreases gradually, and the axial force of the NPR anchor cable increases sharply; however, the sliding surface does not produce relative displacement.

Stage 3 (relative displacement of 16-1101 slip surface): the slope has reached the safety threshold because of the shovel excavation, microcracks appear in the rock mass, relative displacement of the slip surface begins to appear, and the axial force of the NPR anchor cable increases suddenly.

Stage 4 (16-1101 landslide facing slip warning): the sliding surface completely losses its stability and sends out early warning information.

In summary, the actual monitoring results and simulation results are in close agreement, providing a theoretical and practical basis for the mechanistic analysis and numerical simulation calculation of other similar slopes.

4.2.4. Landslide Numerical Simulation Based on 3DEC. The NPR anchor cable model was constructed by 3DEC software, and the static tension and mechanical characteristics were simulated, as shown in Figure 21.

The boundary of the old landslide body and "16-1101 landslide body" and the boundary of the excavation area of the shovel are shown in Figure 22.

The NPR anchor parameters are listed in Table 4.

The rock mechanical parameters are listed in Table 5 .

(1) The double-sliding model is shown below (Figure 23). 
TABLE 4: Parameters of anchor cable.

\begin{tabular}{ccccc}
\hline Anchor cable & Length $(\mathrm{m})$ & Inclination $\left(^{\circ}\right)$ & Preload $(\mathrm{kN})$ & Value of consistence $(\mathrm{kN})$ \\
\hline 75 & 30 & 400 & 850 \\
\hline
\end{tabular}

TABle 5: Parameters of rock mechanics.

\begin{tabular}{lcccccc}
\hline Rock mass name & $\begin{array}{c}\text { Bulk weight } \\
\left(\mathrm{kg} / \mathrm{m}^{3}\right)\end{array}$ & Bulk modulus $(\mathrm{GPa})$ & Shear modulus $(\mathrm{GPa})$ & Cohesion $(\mathrm{kPa})$ & Friction angle $\left(^{\circ}\right)$ & Tensile strength $(\mathrm{MPa})$ \\
\hline Basement & 2900 & 40 & 18 & 420 & 36 & 1.5 \\
Sliding mass & 2500 & 20 & 8 & 70 & 27 & 0.2 \\
\hline
\end{tabular}

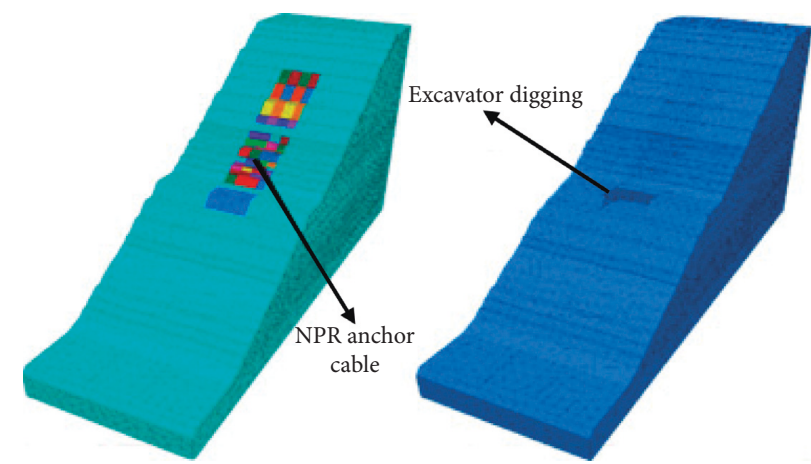

FIGURE 23: Double-sliding model created by 3DEC.

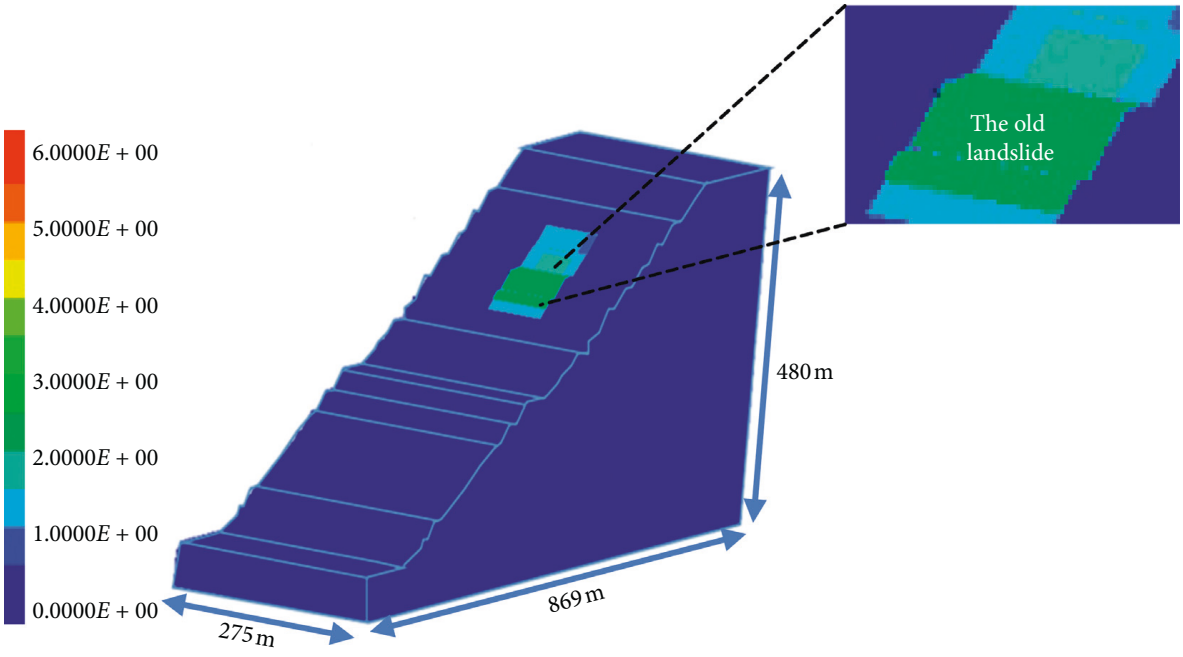

FIgURe 24: Displacement contour after landslide stabilization.

(1) Analysis of the Simulation Results

(i) The Mohr-Coulomb elastic-plastic model was used to observe the displacement contours of the slip surface, settlement curve, and NPR cable axial force curve.

(ii) The sign of the stability of the slope is that the subsidence curve does not change, but the calculation is continued.

As shown in Figure 24, the maximum displacement of the old landslide is $1.2 \mathrm{~m}$ after stabilization. The landslide body is basically located at the set position of the contact surface of the model. When the landslide starts, the strength of the contact surface is set to the actual strength of the sliding surface and then slides to the stable state. Because of the reinforcement of multiple anchor cables with constant resistance and large deformation, the 161101 sliding body does not slip and disintegrate as a whole, but only emerges from the tongue. In the present extrusion failure mode, tension fracture occurs in the middle and rear edges.

(iii) Numerical simulation analysis of "16-1101 landslide"

The speed and deformation of the old landslide body set to zero to fully consider the effect of the accumulated load caused by the old landslide body. The numerical simulation of the "16-1101 landslide" started, and the typical three- 


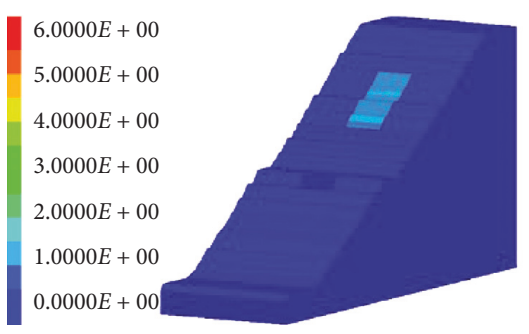

Step 9401

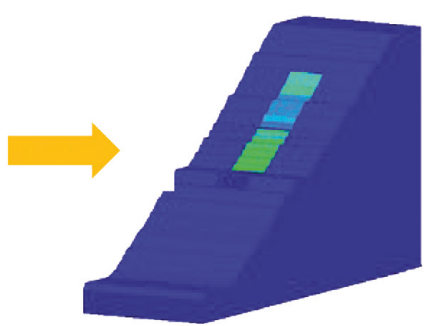

Step 22401

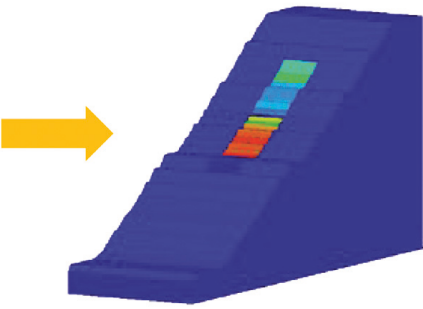

Step 29401

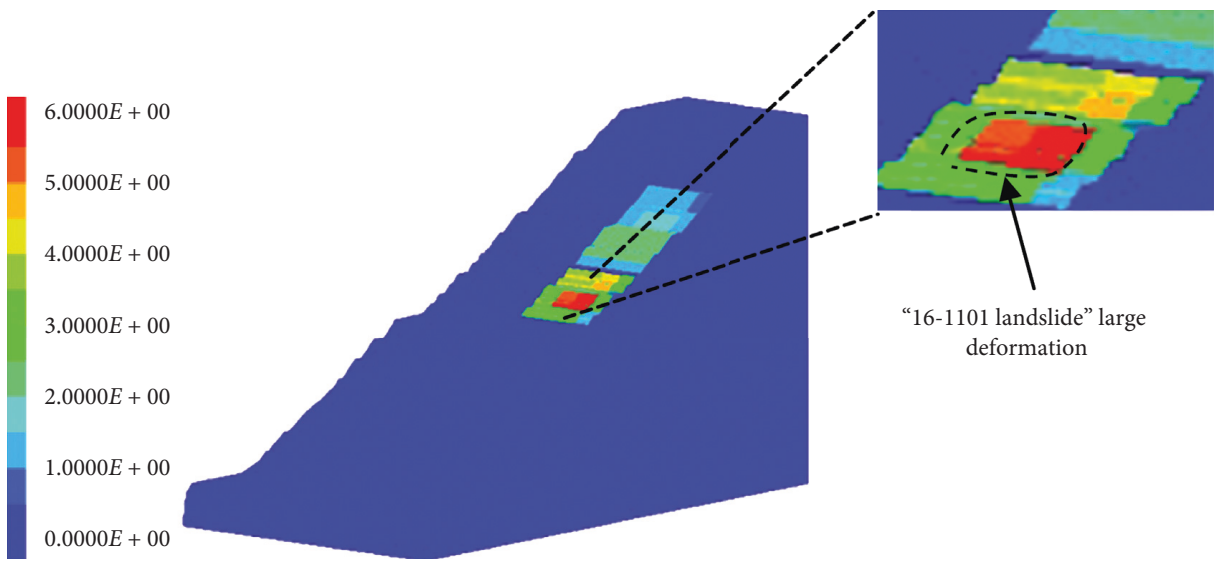

FIgURE 25: 16-1101 landslide instability displacement contour.

TABLE 6: Criteria of strength degradation stages.

\begin{tabular}{lcccc}
\hline Stage classification & Normal stiffness $(\mathrm{GPa})$ & Tangential stiffness $(\mathrm{GPa})$ & Cohesive strength $(\mathrm{kPa})$ & Friction angle $\left(^{\circ}\right)$ \\
\hline First stage & 9 & 14 & 148 & 21 \\
Second stage & 9 & 12 & 36 & 25 \\
Third stage & 9 & 10 & 18 & 19 \\
Fourth stage & 9 & 8 & & 18 \\
\hline
\end{tabular}

step process was used to reproduce the entire landslide instability process.

The "16-1101 landslide" started as a second landslide after the instability of the old landslide body in the upper part. Figure 25 shows the displacement change contour (intercepting steps 9401, 22401, and 29401), and the final displacement contour of the landslide more intuitively shows the whole process of the "16-1101 landslide" instability. The direct cause of the ultimate instability of the whole slope is the penetration of the sliding surface, and the antisliding force is less than the sliding force, gradually deteriorating the strength of the old landslide body. Therefore, in practical calculation, the strength of the contact surface (sliding surface) should be weakened to decrease the rock mass instability. The strength of the contact surface should be divided into stages from the stable state to the final sliding state, as listed in Table 6 .

After the start of "16-1101 landslide," the axial force variation characteristics of the NPR anchor cable, the elongation variation curve of the anchor cable, the vertical relative displacement curve of monitoring point 1 on the upper edge of the old landslide body, and the vertical relative displacement curve of monitoring point 2 on the upper edge of "16-1101 landslide" are shown in Figure 26.

Figure 27 shows the monitoring point 1 of the subsidence at the upper edge of the old landslide body and monitoring point 2 of the subsidence at the upper edge of the "16-1101 landslide." follows:

The four stages shown in Figure 26 are summarized as

Stage 1 (shovel excavation at the foot of the slope): the slope body is affected by the disturbance of shovel excavation on $430 \mathrm{~m}$ steps. The axial force of the NPR anchor cable increases from $400 \mathrm{kN}$ to $530 \mathrm{kN}$, and its elongation reaches $0.3 \mathrm{~m}$. The sliding distance is $0.6 \mathrm{~m}$. Stage 2 (revival of the old sliding body): with the excavation of the electric shovel, the sliding force of the slope rock mass increases and then the old sliding body revives, the strength of weak sliding surface decreases gradually, and the axial force of the NPR anchor cable increases sharply; the curve of the axial force monitoring increases rapidly to $680 \mathrm{kN}$, the elongation of the anchor cable reaches $0.64 \mathrm{~m}$, and the relative displacement of sliding surface is $1.54 \mathrm{~m}$. 


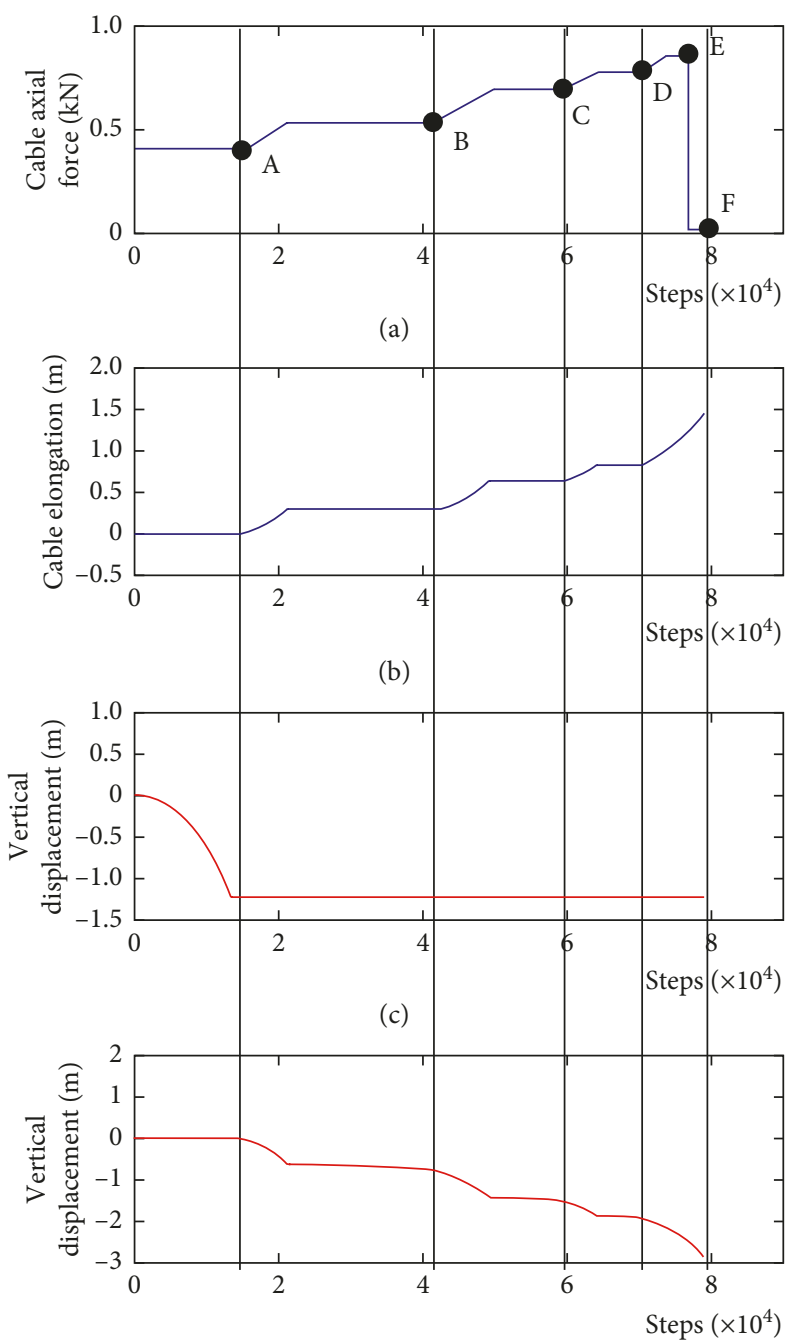

(d)

FIGURE 26: Monitoring curve of 16-1101 landslide by 3DEC software: (a) anchor cable force; (b) anchor cable elongation; (c) vertical relative displacement of monitoring point 1; (d) vertical relative displacement of monitoring point 2 .

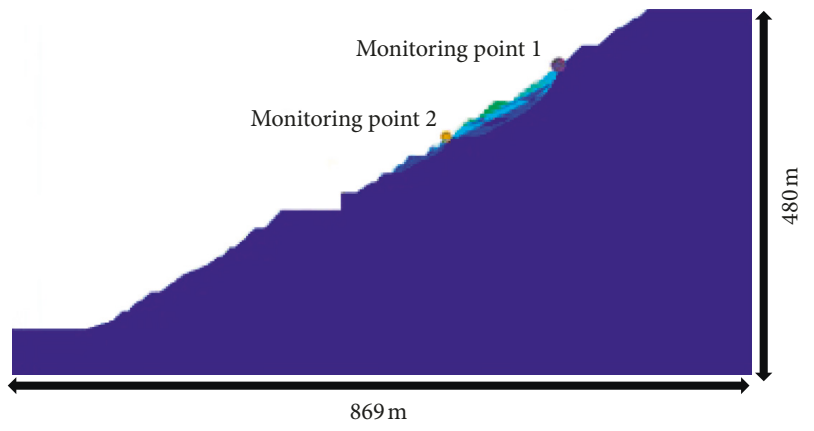

Figure 27: Layout of the landslide settlement.

Stage 3 (relative displacement of the 16-1101 slip surface): the slope reached the safety threshold because of shovel excavation. There are microcracks in the rock mass. The slip surface begins to displace relatively. The axial force of the NPR anchor cable rises rapidly to $770 \mathrm{kN}$, the elongation of the anchor cable reaches
$0.84 \mathrm{~m}$, and the slip body generates a relative displacement of $1.87 \mathrm{~m}$ along the potential slip surface.

Stage 4 (16-1101 slope near landslide warning): the axial force of the NPR anchor cable continues to rise to a constant resistance of $850 \mathrm{kN}$. When the relative displacement of the sliding surface reaches $2.54 \mathrm{~m}$, the sliding surface completely losses stability, the anchor cable fails, the axial force suddenly drops to $18 \mathrm{kN}$, and the anchor cable extends to $1.45 \mathrm{~m}$, eventually sending out warning information.

According to the landslide process, three typical steps are selected in the displacement slice contour to reproduce the landslide process, as shown in Figure 28.

The slope failure simulated by $3 \mathrm{DEC}$ is in close agreement to the field investigation parameters: "16-1101 landslide" has an actual settlement of $3.5 \mathrm{~m}$ at the top; the slope of the middle part is broken, and the crack zone appears; the sinking amount is $12 \mathrm{~m}$; a compression deformation zone is formed at the bottom, and a settlement is in the range $2-3 \mathrm{~m}$. It is accumulated at a 


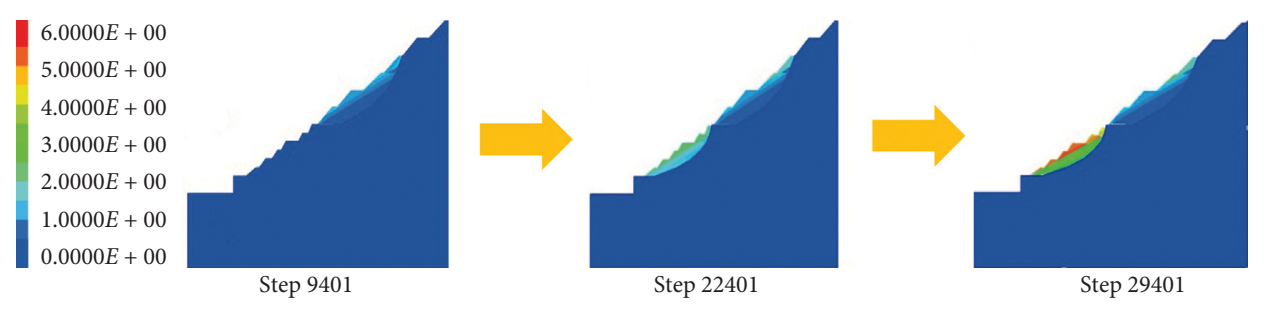

FIGURE 28: Key point displacement slice contour.

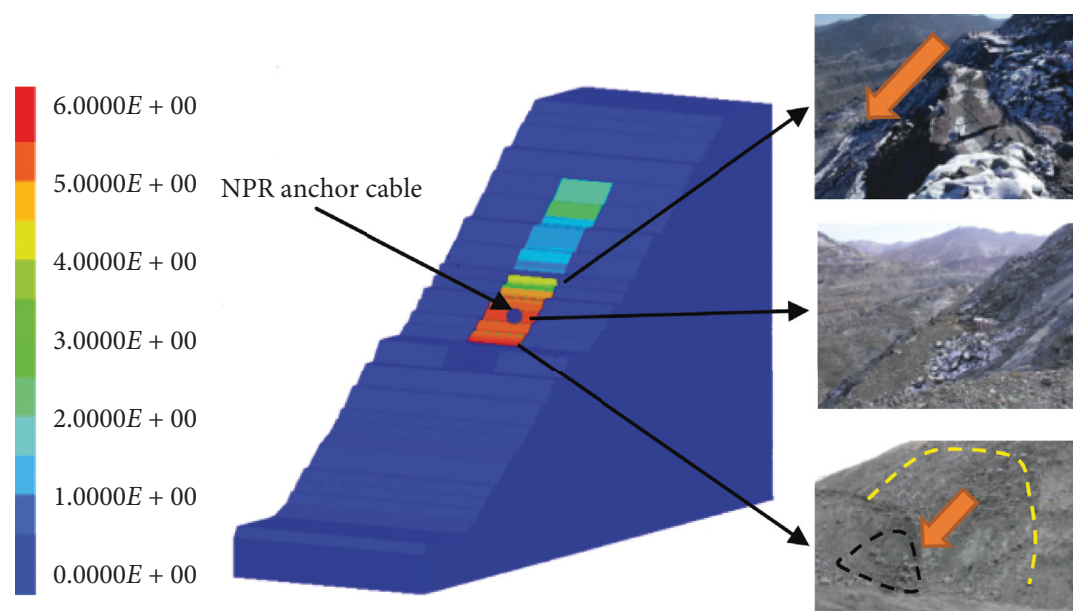

FIGURE 29: Comparison of simulation results with field conditions.

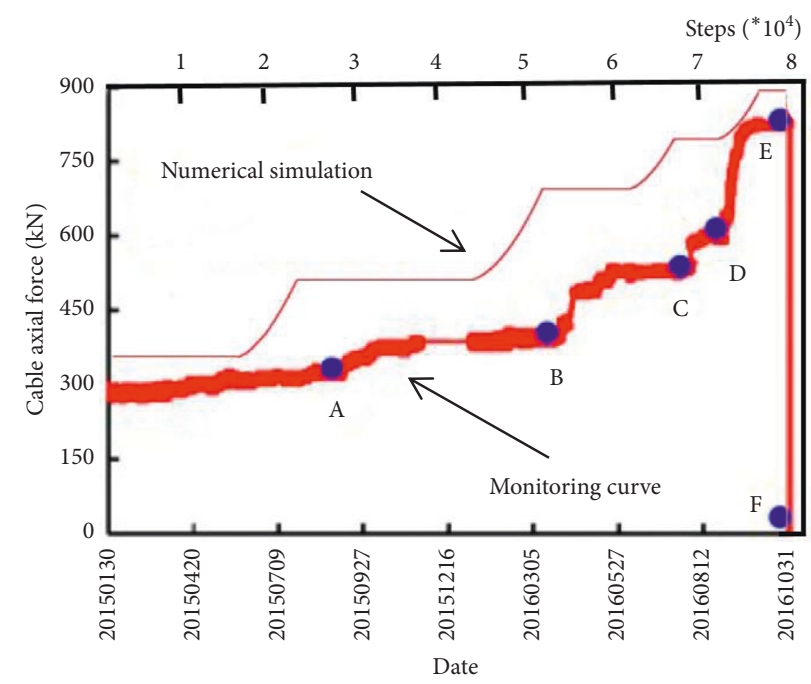

Figure 30: Comparison of numerical simulation curve and monitoring curve.

height of $430 \mathrm{~m}$ platform at the bottom. Figure 29 shows that the simulation results are consistent with the actual field situation.

The NPR anchor cables built at $478 \mathrm{~m}$ steps in the landslide body were further selected, and numerical simulation was performed on the whole process of landslide. The change in the axial force curve was observed (Figure 30), indicating that the curves were significantly consistent with the field monitoring curves, providing a theoretical and practical basis for the analysis of landslide mechanism and numerical simulation calculation of other similar slopes.
4.3. Comparison of the Simulation Results Obtained by FLAC3D and 3DEC Software. The whole landslide process was simulated and analyzed by FLAC3D and 3DEC software. The monitoring curve characteristics and the landslide displacement distribution contour obtained by the two software were compared as follows.

4.3.1. Comparison of the Monitoring Curves. The axial force changes in the NPR anchor cables were monitored by 


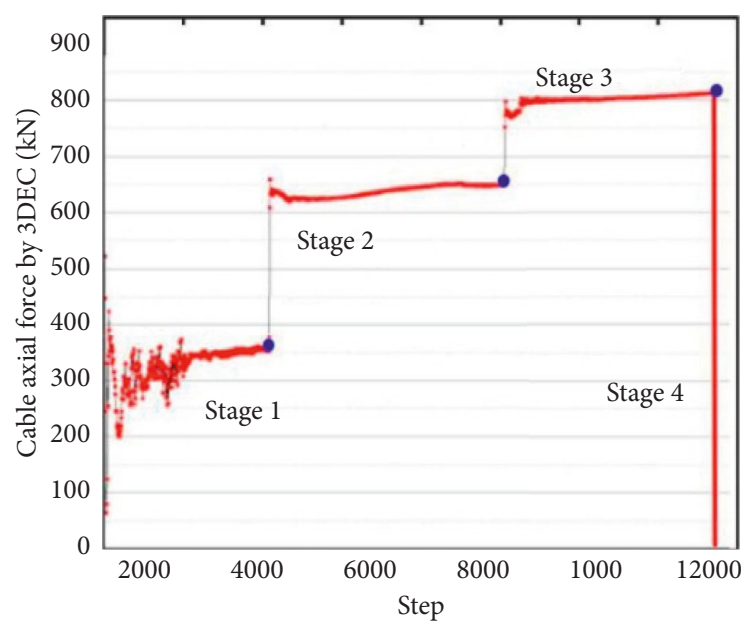

(a)

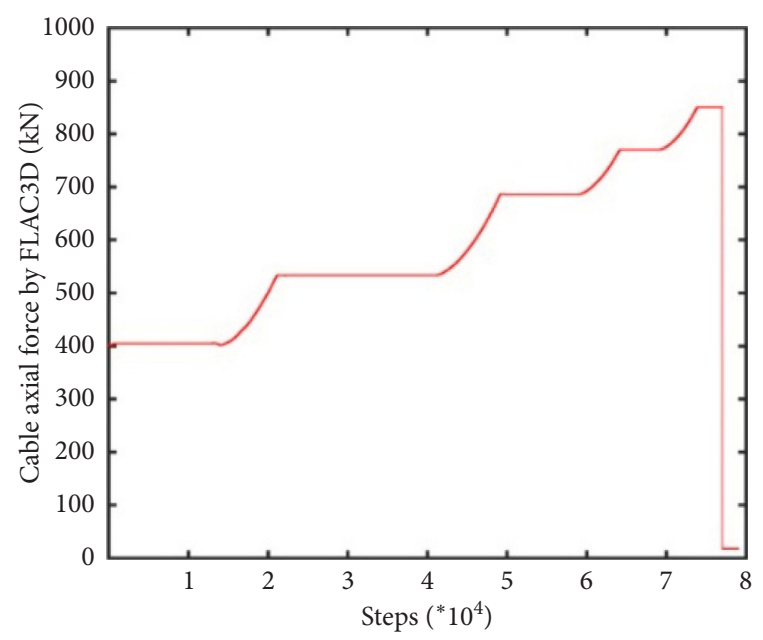

(b)

Figure 31: Comparison of the axial force variation curve of the NPR anchor cable.

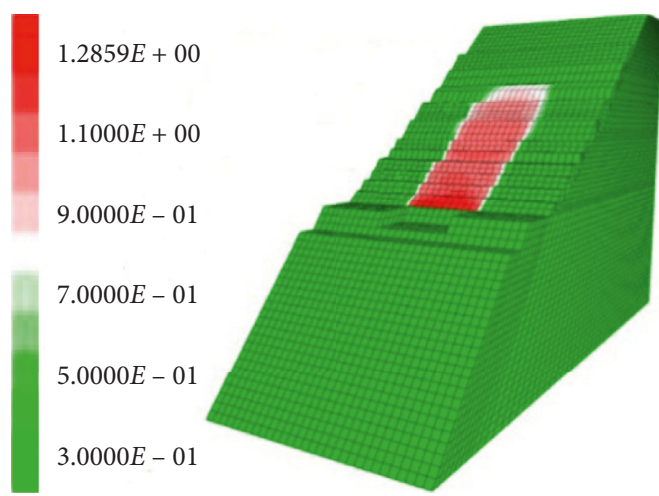

(a)

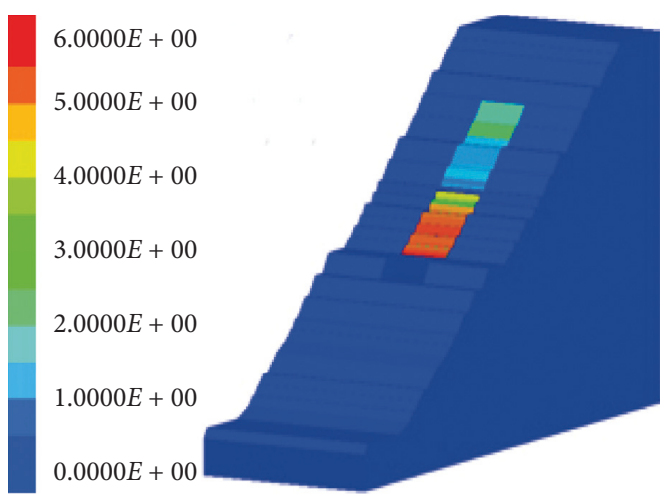

(b)

FIgURE 32: Comparison of displacement distribution contour after the landslide instability process.

FLAC3D and 3DEC software. The comparison shows that both have four different degrees of cracks, with identical curve trend and characteristics. As shown in Figure 31, the curves of the axial force variation of the anchor cables were simulated by FLAC3D and 3DEC software in Figures 31(a) and $31(\mathrm{~b})$, respectively.

\subsubsection{Comparison of Landslide Displacement Contour.} The landslide instability process was also simulated by FLAC3D software and 3DEC software, as shown in Figure 32. Figure 32 (a) is simulated by FLAC3D, and the maximum deformation is $\sim 5 \mathrm{~m}$; Figure 32 (b) is simulated by $3 \mathrm{DEC}$, and the maximum displacement is $\sim 6 \mathrm{~m}$, showing a very small difference.

\section{Conclusions}

In this study, numerical simulation was carried out on the whole process of large deformation and failure of 16-1101 landslide, and the following conclusions were obtained:
(1) Based on the theory of Cataclysm mechanics, a large deformation numerical calculation model of the NPR anchor cable was constructed, and the simulated curve has a significant constant resistance effect, confirming that the large deformation can be achieved without damage.

(2) The numerical analysis model of the NPR anchor cable with constant resistance large deformation was constructed by Fish language in the finite element numerical simulation software FLAC3D, and it is embedded in the "2016-1101 landslide," achieving the numerical simulation of monitoring and warning of Newtonian force. The comparison between the numerical simulation results and the field measurement results shows good agreement between the simulation monitoring curve and the field monitoring curve and proves that this model can be used to monitor the landslide model of Nanfen open-pit mine.

(3) The numerical calculation model of the NPR anchor cable was constructed by the discrete element 
software 3DEC. The numerical simulation monitoring curve of the anchor cable force shows four times of rise and one time of decline, coinciding with the field monitoring curve. The numerical simulation calculation of the whole process monitoring and early warning target of 16-1101 landslide in Nanfen open-pit iron mine was realized, indicating that the model can be used in Nanfen open-pit mine.

(4) The numerical simulation results of the landslide by FLAC3D and 3DEC software were compared and analyzed, indicating a significant consistency between them. The characteristic cracks are relatively consistent, and the trend of landslide also coincides. The maximum deformation is in the range $5-6 \mathrm{~m}$, with a small difference, thus providing a theoretical and practical basis for the mechanistic analysis and numerical simulation of other similar slopes.

\section{Data Availability}

The data used to support the findings of this study are included within the article.

\section{Conflicts of Interest}

The authors declare that they have no conflicts of interest.

\section{Acknowledgments}

This study was supported by the Zhejiang Province Key R\&D Projects (No. 2019C03104) and the Fundamental Research Funds for the Central Universities, SCUT (No. 2015QB02).

\section{References}

[1] Y. Li, S. Zhang, and X. Zhang, "Classification and fractal characteristics of coal rock fragments under uniaxial cyclic loading conditions," Arabian Journal of Geosciences, vol. 11, no. 9, p. 201, 2018

[2] Z. Qin, H. Fu, and X. Chen, "A study on altered granite mesodamage mechanisms due to water invasion-water loss cycles," Environmental Earth Sciences, vol. 78, no. 14, p. 428, 2019.

[3] J. Wang, S.-c. Li, L.-p. Li, P. Lin, Z.-h. Xu, and C.-l. Gao, "Attribute recognition model for risk assessment of water inrush," Bulletin of Engineering Geology and the Environment, vol. 78, no. 2, pp. 1057-1071, 2019.

[4] S. Zhang, Y. Li, B. Shen, X. Sun, and L. Gao, "Effective evaluation of pressure relief drilling for reducing rock bursts and its application in underground coal mines," International Journal of Rock Mechanics and Mining Sciences, vol. 114, pp. 7-16, 2019.

[5] W. Sun, H. Du, F. Zhou, and J. Shao, "Experimental study of crack propagation of rock-like specimens containing conjugate fractures," Geomechanics and Engineering, vol. 17, pp. 323-331, 2019.

[6] X. J. Yang, C. W. Hu, M. C. He et al., "Study on presplitting blasting the roof strata of adjacent roadway to control roadway deformation," Shock and Vibration, vol. 2019, Article ID 3174898, 16 pages, 2019.

[7] T. Kamai, "Monitoring the process of ground failure in repeated landslides and associated stability assessments," Engineering Geology, vol. 50, no. 1-2, pp. 71-84, 1998.
[8] R. Ohbayashi, Y. Nakajima, H. Nishikado, and S. Takayama, "Monitoring system for landslide disaster by wireless Sensing node network," in Proceedings of the 2008 SICE Annual Conference, pp. 1704-1710, Tokyo, Japan, August 2008.

[9] G. Puglisi, A. Bonaccorso, M. Mattia et al., "New integrated geodetic monitoring system at Stromboli volcano (Italy)," Engineering Geology, vol. 79, no. 1-2, pp. 13-31, 2005.

[10] B. A. Reevea, G. F. Stickley, D. A. Noon, and I. D. Longstaff, "Developments in monitoring mine slope stability using radar interferometry," in Proceedings of the 2000 IEEE International Geoscience and Remote Sensing Symposium, pp. 2325-2327, Honolulu, HI, USA, July 2000.

[11] P. Allasia, A. Manconi, D. Giordan, M. Baldo, and G. Lollino, "ADVICE: a new approach for near-real-time monitoring of surface displacements in landslide hazard scenarios," Sensors, vol. 13, no. 7, pp. 8285-8302, 2013.

[12] S. Choon, Y. Jung, P. Hyeong-Dong, and Y. Choi, "Failure prediction for weak rock slopes in a large open-pit mine by GPS measurements and assessment of landslide susceptibility," The Journal of Engineering Geology, vol. 20, pp. 243-255, 2010.

[13] M. E. Hartwig, "Detection of mine slope motions in Brazil as revealed by satellite radar interferograms," Bulletin of Engineering Geology and the Environment, vol. 75, no. 2, pp. 605-621, 2016.

[14] T. Carlà, V. Tofani, L. Lombardi et al., "Combination of GNSS, satellite InSAR, and GBInSAR remote sensing monitoring to improve the understanding of a large landslide in high alpine environment," Geomorphology, vol. 335, pp. 62-75, 2019.

[15] L. He, L. Wu, S. Liu, Z. Wang, C. Su, and S.-N. Liu, "Mapping two-dimensional deformation field time-series of large slope by coupling DInSAR-SBAS with MAI-SBAS," Remote Sensing, vol. 7, no. 9, pp. 12440-12458, 2015.

[16] A. Michelini, N. Coli, F. Coppi et al., "Advanced data processing of ground-based synthetic aperture radar for slope monitoring in open pit mines," in Proceedings of the 2015 24th International Mining Congress of Turkey, pp. 420-427, Antalya, Turkey, April 2015.

[17] S. J. Miao, X. Hao, X. L. Guo, Z. M. Wang, and M. C. Liang, "Displacement and landslide forecast based on an improved version of Saito's method together with the Verhulst-Grey model," Arabian Journal of Geosciences, vol. 10, no. 3, p. 53, 2017.

[18] M. He, W. Gong, J. Wang et al., "Development of a novel energy-absorbing bolt with extraordinarily large elongation and constant resistance," International Journal of Rock Mechanics and Mining Sciences, vol. 67, pp. 29-42, 2014.

[19] M. He, C. Li, W. Gong, L. R. Sousa, and S. Li, "Dynamic tests for a Constant-Resistance-Large-Deformation bolt using a modified SHTB system," Tunnelling and Underground Space Technology, vol. 64, pp. 103-116, 2017.

[20] M. He, Y. Wang, and Z. Tao, "A new early-warning prediction system for monitoring shear force of fault plane in the active fault," Journal of Rock Mechanics and Geotechnical Engineering, vol. 2, no. 3, pp. 223-231, 2010.

[21] M. C. He, Y. J. Wan, J. Yang, P. Zhou, Q. Gao, and Y. B. Gao, "Comparative analysis on stress field distributions in roof cutting non-pillar mining method and conventional mining method," Journal of China Coal Society, vol. 43, pp. 626-637, 2018.

[22] Z. G. Tao, C. Zhu, X. H. Zheng, and M. C. He, "Slope stability evaluation and monitoring of Tonglushan ancient copper mine relics," Advances in Mechanical Engineering, vol. 10, no. 8, pp. 1-16, 2018. 
[23] Z. G. Tao, Z. Zhu, W. S. Han et al., "Static tension test and the finite element analysis of constant resistance and large deformation anchor cable," Advances in Mechanical Engineering, vol. 10, no. 12, pp. 1-13, 2018.

[24] Z. G. Tao, C. Zhu, Y. Wang, J. M. Wang, M. C. He, and B. Zhang, "Research on stability of an open-pit mine dump with fiber optic monitoring," Geofluids, vol. 2018, Article ID 9631706, 20 pages, 2018.

[25] Z. Tao, Y. Wang, C. Zhu, H. Xu, G. Li, and M. He, "Mechanical evolution of constant resistance and large deformation anchor cables and their application in landslide monitoring," Bulletin of Engineering Geology and the Environment, vol. 78, no. 7, pp. 4787-4803, 2019.

[26] Z. Li, Y. Jiang, Z. Tao, and M. He, "Monitoring prediction of a rockslide in an open-pit mine and numerical analysis using a material instability criterion," Bulletin of Engineering Geology and the Environment, vol. 78, no. 3, pp. 2041-2053, 2019b.

[27] B. Maihemuti, E. Z. Wang, T. Hudan, and Q. J. Xu, "Numerical simulation analysis of reservoir bank fractured rockslope deformation and failure processes," International Journal of Geomechanics, vol. 16, no. 2, 2016.

[28] J. Li, Y. Gao, Y. Li, B. Cui, and Z. Deng, "Intelligent back analysis of constitutive parameters for soil slope based on unified strength theory," in Proceedings of the 2011 2nd ISRM International Young Scholars' Symposium on Rock Mechanics, Rock Mechanics: Achievements and Ambitions, pp. 941-945, Beijing, China, October 2011.

[29] T.-H. Yang, W.-H. Shi, P.-T. Wang, H.-L. Liu, Q.-L. Yu, and Y. Li, "Numerical simulation on slope stability analysis considering anisotropic properties of layered fractured rocks: a case study," Arabian Journal of Geosciences, vol. 8, no. 8, pp. 5413-5421, 2015.

[30] L. Jing, "A review of techniques, advances and outstanding issues in numerical modelling for rock mechanics and rock engineering," International Journal of Rock Mechanics and Mining Sciences, vol. 40, no. 3, pp. 283-353, 2003.

[31] D. Stead, J. S. Coggan, and E. Eberhardt, "Realistic simulation of rock slope failure mechanisms: the need to incorporate principles of fracture mechanics," International Journal of Rock Mechanics and Mining Sciences, vol. 41, no. 3, p. 466, 2004.

[32] D. Stead, E. Eberhardt, and J. S. Coggan, "Developments in the characterization of complex rock slope deformation and failure using numerical modelling techniques," Engineering Geology, vol. 83, no. 1-3, pp. 217-235, 2006.

[33] A. Munjiza, T. Bangash, and N. W. M. John, "The combined finite-discrete element method for structural failure and collapse," Engineering Fracture Mechanics, vol. 71, no. 4-6, pp. 469-483, 2001.

[34] M. Barla, G. Piovano, and G. Grasselli, "Rock Slide Simulation with the combined finite-discrete element method," International Jounal of Geomechanics, vol. 12, pp. 711-721, 2011.

[35] D. Elmo, D. Stead, E. Eberhardt, and A. Vyazmensky, "Applications of finite/discrete element modeling to rock engineering problems," International Journal of Geomechanics, vol. 13, no. 5, pp. 565-580, 2013.

[36] O. K. Mahabadi, A. Lisjak, A. Munjiza, and G. Grasselli, "YGeo: new combined finite-discrete element numerical code for geomechanical applications finite-discrete element numerical code for geomechanical applications," International Journal of Geomechanics, vol. 12, no. 6, pp. 676-688, 2012.

[37] A. Munjiza, D. R. J. Owen, and N. Bicanic, "A combined finite-discrete element method in transient dynamics of fracturing solids," Engineering Computations, vol. 12, no. 2, pp. 145-174, 1995. 


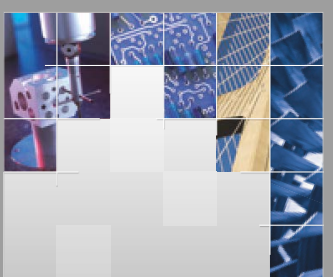

\section{Enfincering}
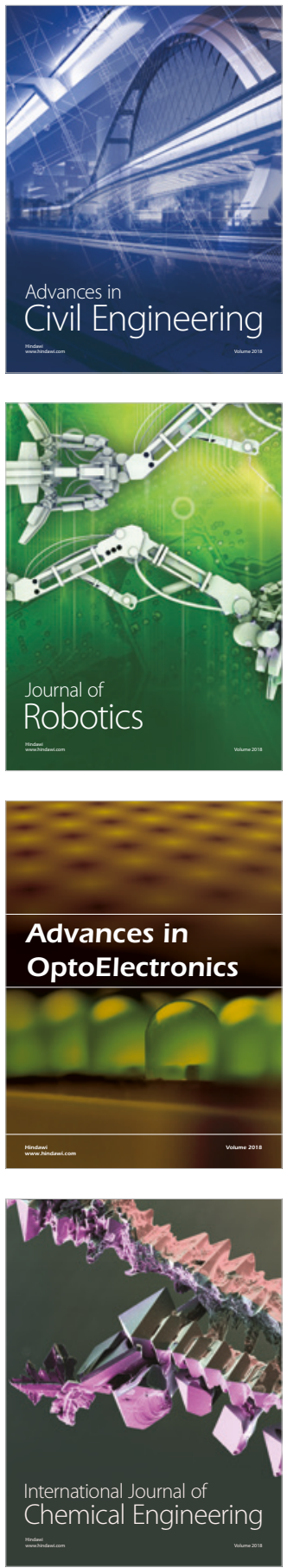

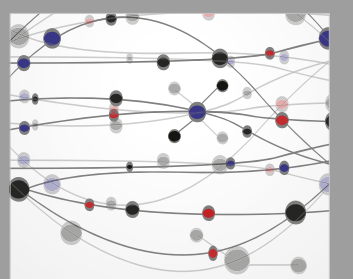

\section{Rotating \\ Machinery}

The Scientific World Journal

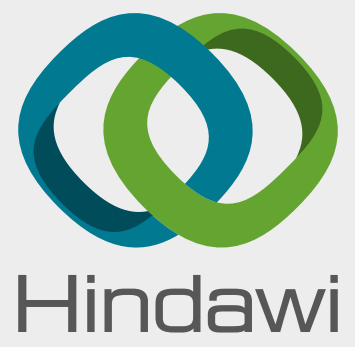

Submit your manuscripts at

www.hindawi.com
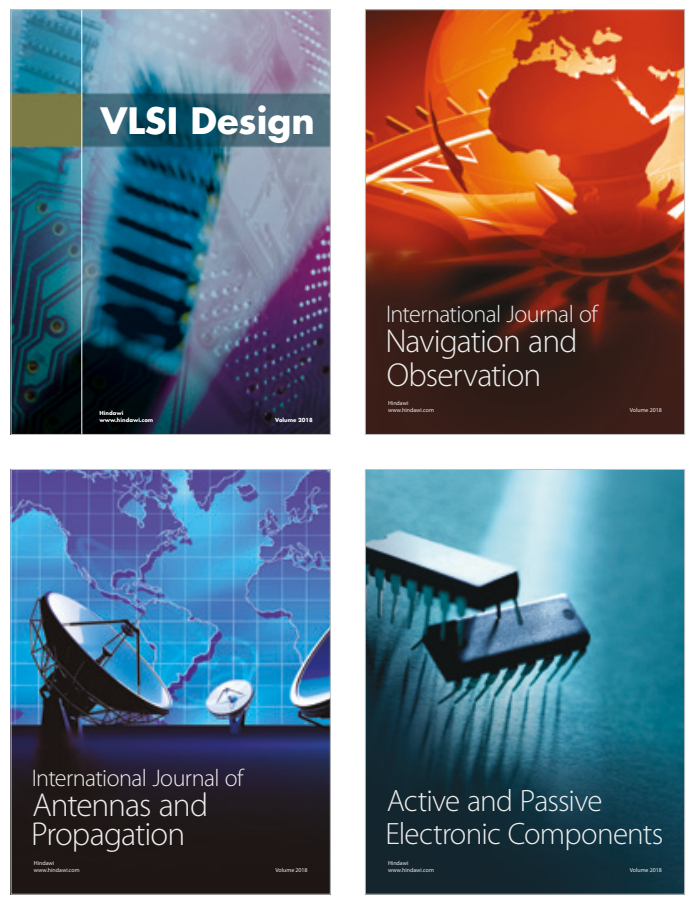
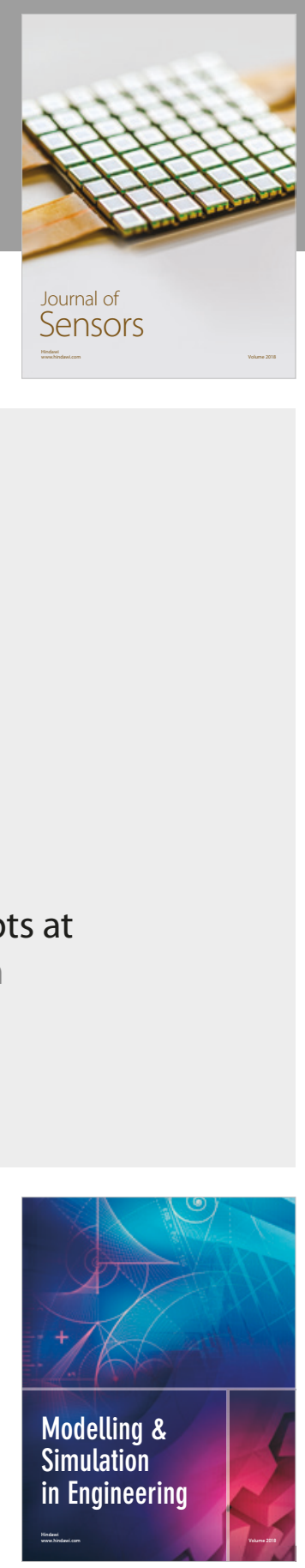

\section{Advances \\ Multimedia}
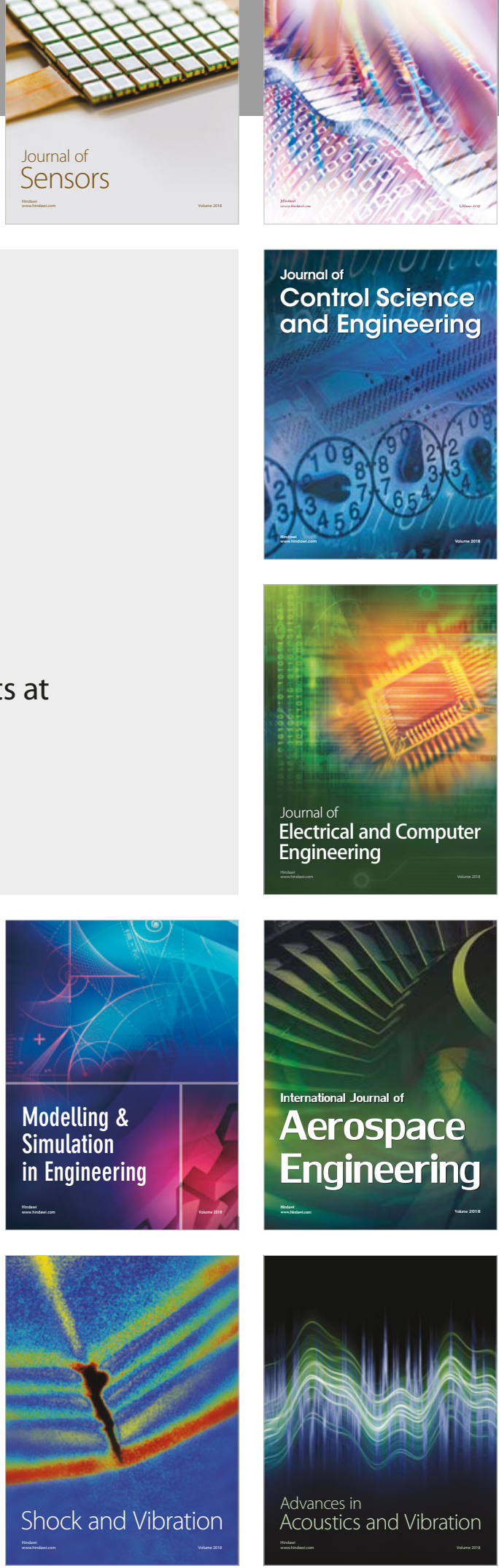